\title{
AGR-2 Data Qualification Report for ATR Cycles 147A, 148A, 148B, and 149A
}

\author{
Michael L. Abbott
}

Binh T. Pham

The INL is a

U.S. Department of Energy

National Laboratory

operated by

Battelle Energy Alliance

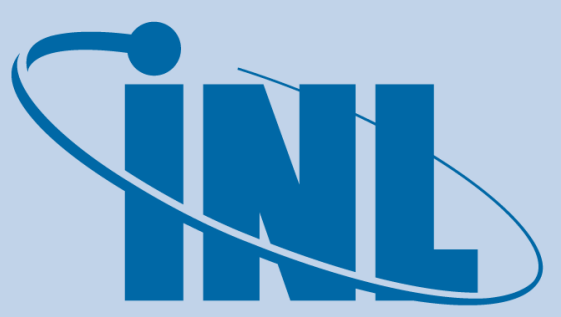

Idaho National Laboratory
August 2011

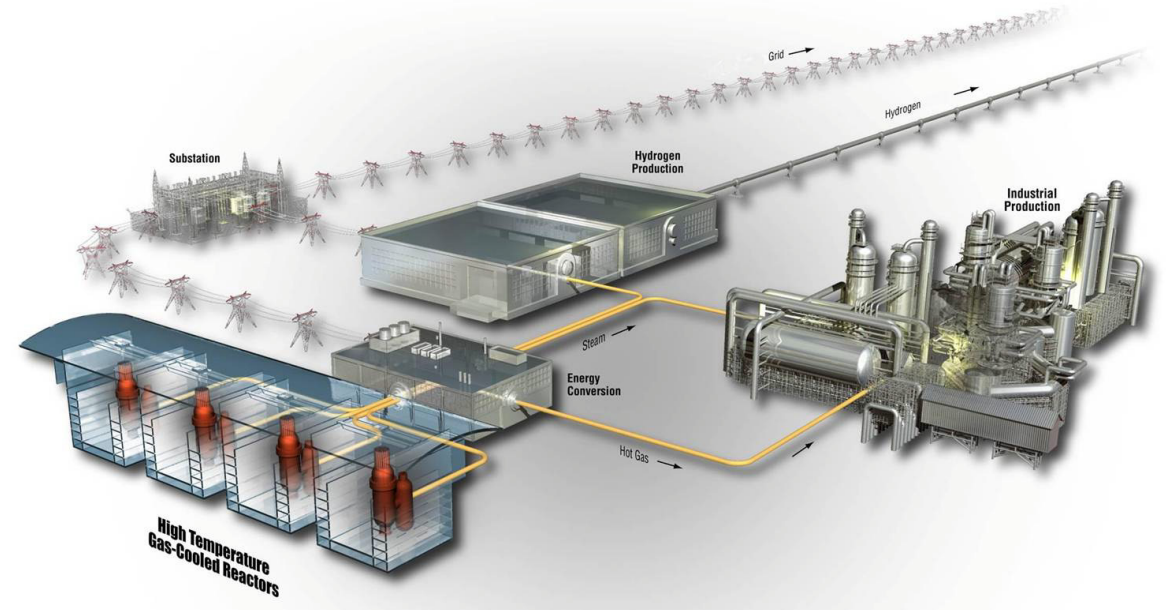




\section{DISCLAIMER}

This information was prepared as an account of work sponsored by an agency of the U.S. Government. Neither the U.S. Government nor any agency thereof, nor any of their employees, makes any warranty, expressed or implied, or assumes any legal liability or responsibility for the accuracy, completeness, or usefulness, of any information, apparatus, product, or process disclosed, or represents that its use would not infringe privately owned rights. References herein to any specific commercial product, process, or service by trade name, trade mark, manufacturer, or otherwise, does not necessarily constitute or imply its endorsement, recommendation, or favoring by the U.S. Government or any agency thereof. The views and opinions of authors expressed herein do not necessarily state or reflect those of the U.S. Government or any agency thereof. 


\title{
AGR-2 Data Qualification Report for ATR Cycles 147A, $148 \mathrm{~A}, 148 \mathrm{~B}$, and 149A
}

\author{
Michael L. Abbott \\ Binh T. Pham
}

August 2011

\begin{abstract}
Idaho National Laboratory
Next Generation Nuclear Plant Project

Idaho Falls, Idaho 83415
\end{abstract}

http://www.inl.gov

Prepared for the

U.S. Department of Energy

Office of Nuclear Energy

Under DOE Idaho Operations Office

Contract DE-AC07-05ID14517 

Next Generation Nuclear Plant Project

AGR-2 Data Qualification Report for ATR Cycles 147A, 148A, 148B, and 149A

INL/EXT-11-22798

August 2011

Approved by:

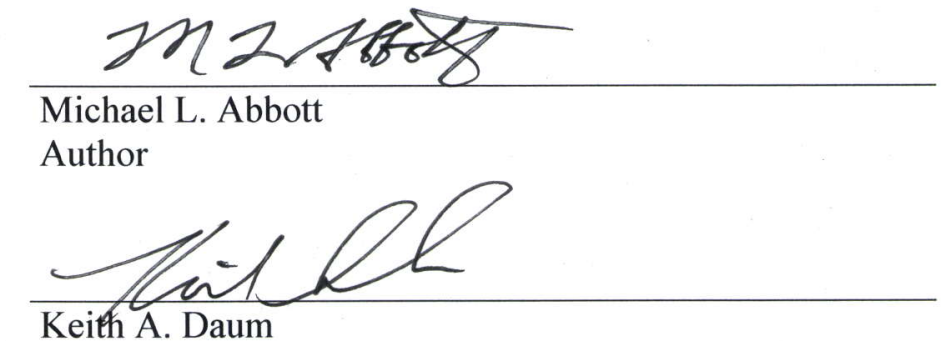

Keith A. Daum

NDMAS Data Review Committee
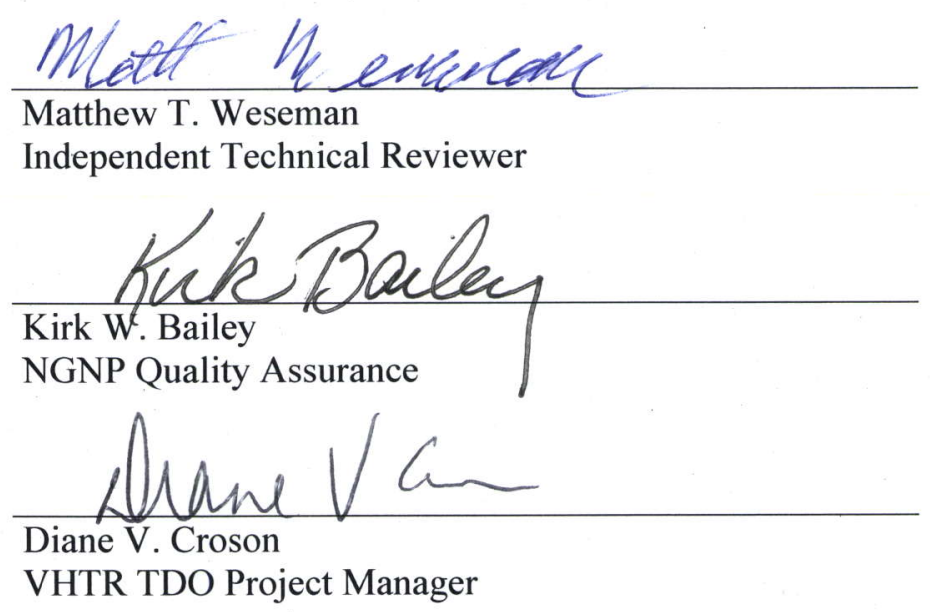

$$
\frac{8-23-20 / 1}{\text { Date }}
$$
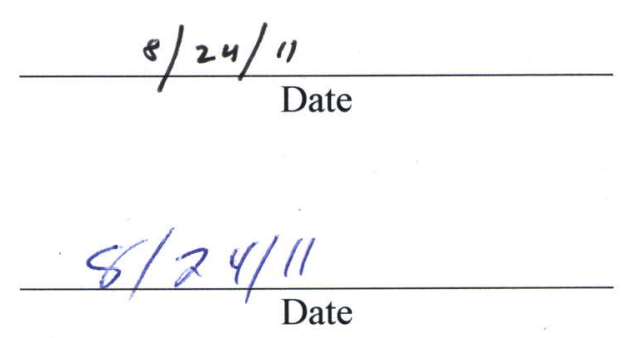

$\frac{8 \cdot 24-2011}{\text { Date }}$

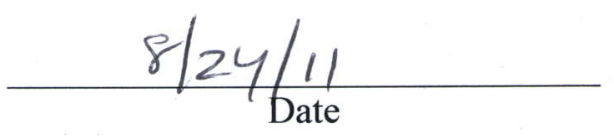





\begin{abstract}
This report presents the data qualification status of fuel irradiation data from the first four reactor cycles (147A, 148A, 148B, and 149A) of the ongoing second Advanced Gas Reactor (AGR-2) experiment, as recorded in and received by the NGNP Data Management and Analysis System (NDMAS). The AGR-2 data streams reported on here include thermocouple temperatures (TC), sweep gas data, and fission product monitoring system (FPMS) data for each of the six capsules in the experiment. A total of 2,439,138 10-min TC and sweep gas data records were received and processed by NDMAS during this time. Of these data, 95.5\% met data collection and accuracy requirements and are labeled as Qualified. There were 109,038 Failed TC records resulting from instrument failure and 4 Failed TC records resulting from NDMAS range test failure. For FPMS data, NDMAS received and processed release rate and preliminary release rate to birth rate ratio $\mathrm{R} / \mathrm{B}$ data for the first three reactor cycles. This data consists of 16,536 release rate records and $12,000 \mathrm{R} / \mathrm{B}$ records for the 12 radionuclides reported. The qualification status of these data has been set to Qualified based on receipt of Quality Assurance-approved Engineering Calculations and Analysis Reports submitted by the FPMS staff. All of the above data have been processed and tested using a SAS ${ }^{\circledR}$-based enterprise application software system, stored in a secure Structured Query Language database, and made available on the NDMAS Web portal (http://ndmas.inl.gov) for both internal and external NGNP project participants.
\end{abstract}




\section{SUMMARY}

This report presents the data qualification status of fuel irradiation data from the first four reactor cycles (147A, 148A, 148B, and 149A) of the ongoing second Advanced Gas Reactor (AGR-2) experiment, as recorded in the Next Generation Nuclear Plant (NGNP) Data Management and Analysis System (NDMAS). AGR-2 is the second in a series of eight planned irradiation experiments for the AGR Fuel Development and Qualification Program, which supports development of the very high temperature gas-cooled reactor under the NGNP Project. NDMAS data processing activities and anomaly testing are described in detail.

The AGR-2 data streams reported on here include thermocouple temperatures, sweep gas data (flow rates, pressure, and moisture content), and fission product monitoring system (FPMS) data (release rates and release rate to birth rate ratios $[\mathrm{R} / \mathrm{Bs}]$ ) for each of the six capsules in the experiment. For all of these data streams, final data qualification status is determined by a Data Review Committee (DRC) comprised of AGR technical leads, NGNP Quality Assurance, and NDMAS analysts. The DRC, which was convened on August 9, 2011, reviewed the data as presented in this report, considered whether the data met the requirements for data collection as specified in Quality Assurance-approved plans, and examined the results of NDMAS data testing and statistical analyses. The DRC independently verified that all data collection met the requirements in the applicable NGNP data collection plans.

A total of 2,439,138 10-min TC and sweep gas data records were received and processed by NDMAS during the first four reactor cycles. Of these data, 95.5\% met data collection and accuracy requirements and are labeled as Qualified. For the thermocouple data, there were 109,038 Failed records resulting from instrument failure and 4 Failed records resulting from NDMAS range test failure (a screening test to identify outliers). For the sweep gas data, there were 568 helium inlet flow rate and 99 capsule outlet flow rate records that failed range testing. All of these gas data were reexamined, found to be valid measurements, and labeled as Qualified.

For FPMS data, NDMAS received and processed release rate and preliminary R/B data for the first three reactor cycles (data for Cycle 4 were still being processed at the time of this report). This data consists of 16,536 release rate records and $12,000 \mathrm{R} / \mathrm{B}$ records for the 12 radionuclides reported $(1,378$ release rate records and 1,000 $\mathrm{R} / \mathrm{B}$ records for each radionuclide). There are an equivalent number of error $(\%)$ records associated with these records. The qualification status of these data has been set to Qualified based on receipt of Quality Assurance-approved Engineering Calculations and Analysis Reports submitted by the FPMS staff.

All of the above data have been processed by a SAS $₫$-based enterprise application software system, stored in a secure Structured Query Language database, and made available on the NDMAS Web portal (http://ndmas.inl.gov). The Web portal presents the data both graphically and in downloadable tables as soon as it is received, provides advanced data analysis and qualification results, and is made available to both internal and external NGNP Project participants. 


\section{CONTENTS}

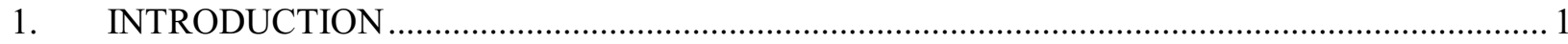

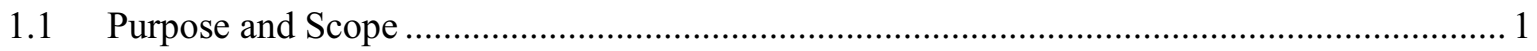

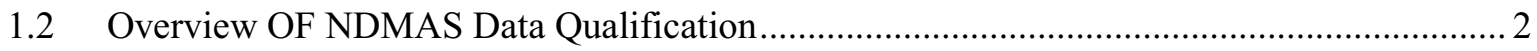

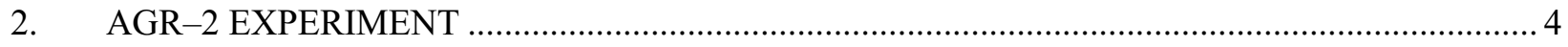

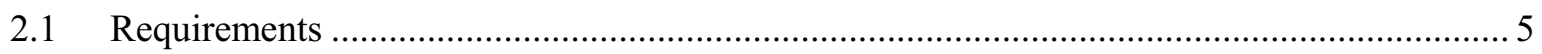

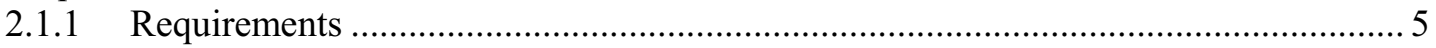

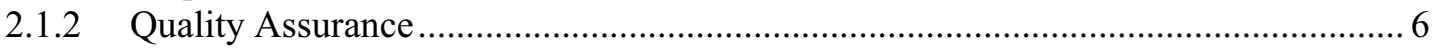

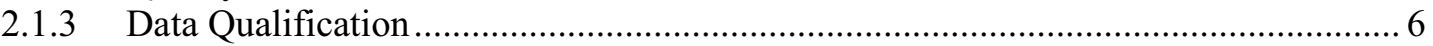

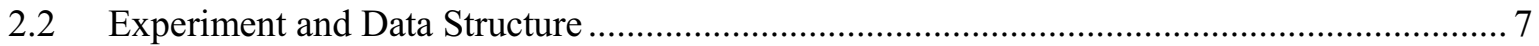

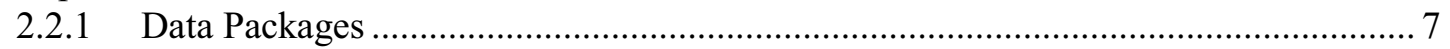

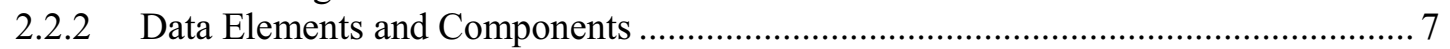

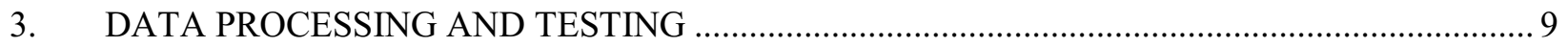

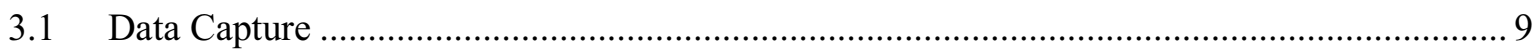

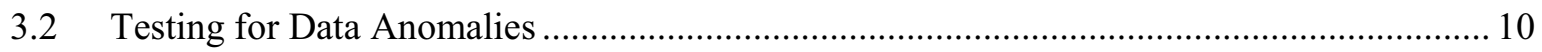

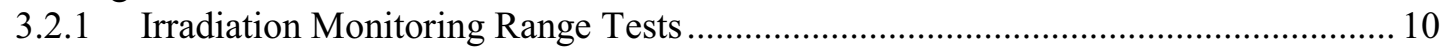

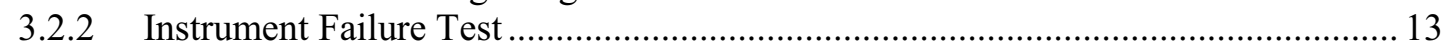

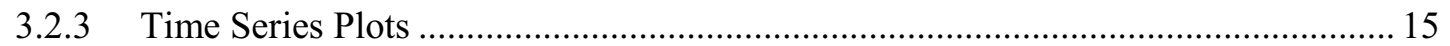

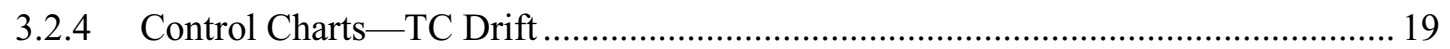

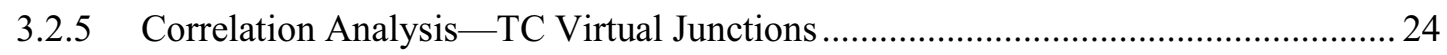

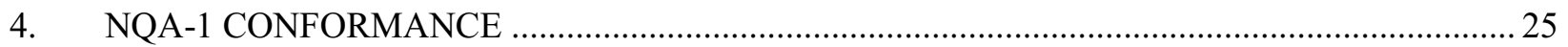

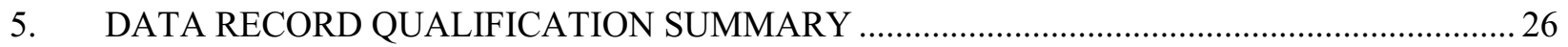

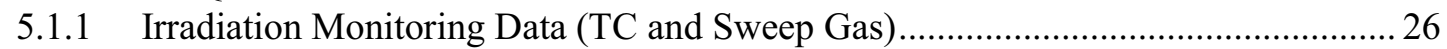

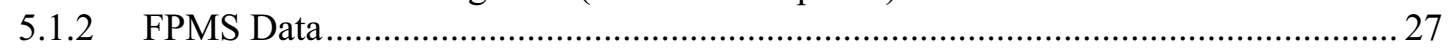

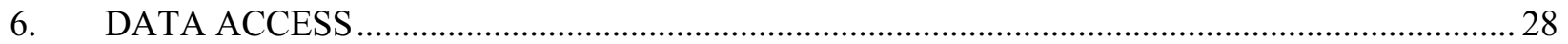

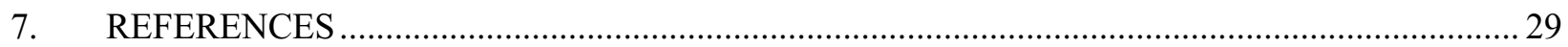

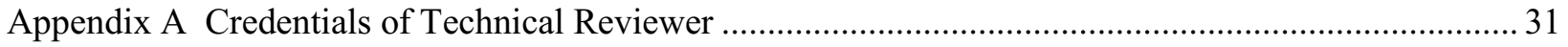

\section{FIGURES}

Figure 1. Radial view of the AGR-2 capsules with TC locations (yellow circles).................................... 4

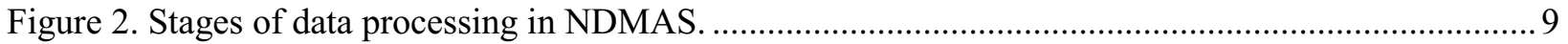

Figure 3. Leakage from the leadout into Capsule 5 is shown by the difference between the helium+neon inlet flow rate (red line) and the capsule outlet flow rate (blue line).................... 13

Figure 4. Failure of TC 5 in Capsule 6 occurred on October 12, 2010 during reactor Cycle 148A.......... 14

Figure 5. Failure of the remaining TC 1 in Capsule 2 occurred during reactor Cycle 148B on November 27, 2010. 
Figure 6. In Capsule 5, both TC 1 and TC 2 failed at approximately 0600 on May 21, 2011, at the conclusion of reactor Cycle 149A. Neither of these TCs responded to full power at the start of reactor Cycle 149B.

Figure 7. Comparisons of daily-average $\mathrm{TC}$ temperatures with $\mathrm{UCO}$ and $\mathrm{UO}_{2}$ temperature specifications in SPC-1064 and TFR-559. .... .16

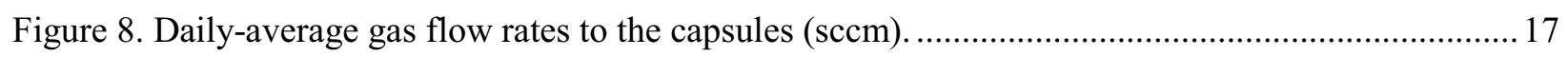

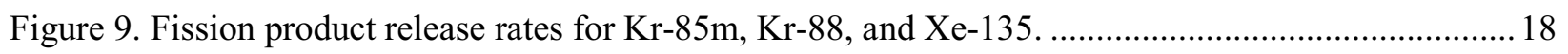

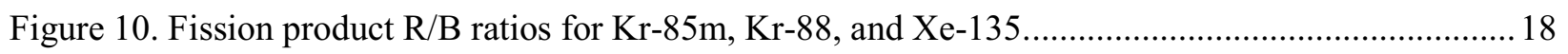

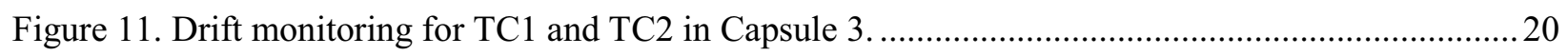

Figure 12. Drift monitoring for TC1 and TC2 in Capsule 5 during the first three cycles......................... 20

Figure 13. Drift monitoring for TC1 and TC2 in Capsule 5 - through Cycle 4. ....................................2 21

Figure 14. Drift monitoring for TC1 and TC4 in Capsule 6 through the third cycle. The TC difference (upper frame) is calculated as TC1-TC4. In the lower frame, TC4 is the dashed green line.

Figure 15. Drift monitoring for TC2 and TC4 in Capsule 6 through the third cycle. The TC difference (upper frame) is calculated as TC2-TC4. In the lower frame, TC4 is the dashed green line.

Figure 16. Drift monitoring for TC3 and TC4 in Capsule 6 through the third cycle. The TC difference (upper frame) is calculated as TC3-TC4. In the lower frame, TC4 is the dashed green line.

Figure 17. Drift monitoring for TC2 and TC4 in Capsule 6 through the fourth cycle. The TC difference (upper frame) is calculated as TC2-TC4. In the lower frame, TC4 is the dashed green line.

Figure 18. Example correlation plot for the TCs $(1,2)$ installed in Capsule 5. Both TCs are most highly correlated with the other TC in the same capsule, indicating no virtual junction.

Figure 19. The AGR-2 Web page (in blue bar on left) on the NDMAS Web portal provides access to numerous types of data reports, graphs, and images.

\section{TABLES}

Table 1. Fuel types in the six AGR-2 capsules (from PLN-3798). 5

Table 2. NDMAS components and response variables for the AGR-2 irradiation monitoring and FPMS data. 8

Table 3. NDMAS tests performed for AGR-2 irradiation monitoring data. 10

Table 4. Range test limits applied to AGR-2 irradiation monitoring data (see Section 1.1.1 Requirements). 11

Table 5. Temperature values $\left({ }^{\circ} \mathrm{C}\right)$ that exceeded test range criteria. 11

Table 6. Gas flow rate data (5-10 min records) that exceeded range test criteria. 12

Table 7. Summary of the qualification status of the 10-min irradiation monitoring records (TC and sweep gas data) received by NDMAS during the first four ATR cycles. 26 


\section{ACRONYMS}

AGR Advanced Gas Reactor

ATR Advanced Test Reactor

DRC Data Review Committee

ECAR Engineering Calculations and Analysis Report

FPMS Fission Production Monitoring System

INL Idaho National Laboratory

NDMAS NGNP Data Management and Analysis System

NQA-1 American Society of Mechanical Engineers Quality Assurance Requirements for Nuclear Facility Applications

NGNP Next Generation Nuclear Plant

PIE post-irradiation examination

QA Quality Assurance

R/B Release Rate To Birth Rate Ratio

SCCM Standard Cubic Centimeters per Minute

SQL Structured Query Language

TC Thermocouple

TFR Technical and Functional Requirements

VHTR Very High Temperature gas-cooled Reactor 


\section{AGR-2 Data Qualification Report for ATR Cycles 147A, $148 \mathrm{~A}, 148 \mathrm{~B}$, and 149A}

\section{INTRODUCTION}

This report presents the data qualification status of fuel irradiation data from the first four reactor cycles (147A, 148A, 148B, and 149A) of the on-going second Advanced Gas Reactor (AGR) experiment as recorded in the Next Generation Nuclear Plant (NGNP) Data Management and Analysis System (NDMAS). This includes data received by NDMAS from the period June 22, 2010, through May 21, 2011. AGR-2 is the second in a series of eight planned irradiation experiments for the AGR Fuel Development and Qualification Program, which supports development of the very high temperature gascooled reactor (VHTR) under the NGNP Project. Irradiation of the AGR-2 test train is being performed in the Advanced Test Reactor (ATR) at Idaho National Laboratory (INL) and is planned for 600 effective full power days (approximately 2.75 calendar years; PLN-3798). The experiment is intended to demonstrate the performance of UCO (uranium oxycarbide) and $\mathrm{UO}_{2}$ (uranium dioxide) fuel produced in a large coater. Data qualification status of the AGR-1 experiment was reported in Abbott et al. (2010).

\subsection{Purpose and Scope}

This report documents the data qualification status of the AGR-2 fuel irradiation monitoring data streams, which include temperature, sweep gas, and fission product monitoring data. Final data qualification status is determined for these data streams by a Data Review Committee (DRC), comprised of project technical leads, Quality Assurance (QA), NDMAS analysts, and an independent technical reviewer (Appendix A). The DRC considers: (1) whether the data meet the requirements for data collection as specified in Test Plans, Test Specifications, Technical and Functional Requirements (TFR), and QA plans; (2) the results of data testing and statistical analyses as performed by the NDMAS; and (3) other QA-approved data reports submitted by data generators such as Engineering Calculations and Analysis Reports (ECARs). All of the above information is summarized in this report. The final DRC findings on data qualification status are documented using FRM-1073, "Data Evaluation Report," which is stored as a record in the INL Electronic Data Management System.

This report describes: (1) data handling within NDMAS after receipt of the data from data generators; (2) the data structure, including data packages, components, attributes, and response variables; (3) NDMAS testing and statistical methods used to help identify possible data anomalies; and (4) the current qualification status of all the AGR-2 data records stored in NDMAS along with summarized information on test results and resolutions.

Fuel irradiation monitoring data reported herein include the following for each of six independently controlled and monitored capsules in the AGR-2 experiment:

- Thermocouple (TC) temperatures (two in each capsule except for capsule 6 which has five)

- Sweep gas (helium, neon, outlet) measurements (mass flow rates, pressure, and moisture content)

- Fission Product Monitoring System (FPMS) krypton and xenon radionuclide release rates (12 isotopes)

- $\quad$ FPMS release-to-birth rate ratios $(\mathrm{R} / \mathrm{Bs})$ for the krypton and xenon isotopes.

The basis for the qualification status of FPMS data is QA-approved ECARs submitted by the FPMS technical staff. These ECARs provide independent verification that the FPMS data submitted to NDMAS meet data collection requirements and conform to NQA-1 (ASME 2008, 2009) requirements. No similar 
ECARs exist for the TC and sweep gas data, so the basis for their data qualification is the DRC review of the data, data testing, and data collection documentation as presented in this report.

This document does not address the qualification status of three additional AGR-2 data streams stored in the NDMAS database: fuel fabrication data, thermal/neutronics simulation data, and post-irradiation examination (PIE) data. All AGR-2 fuel fabrication data were qualified based on INL receipt and review of hard-copy vendor Data Certification Packages. These data have been stored in the NDMAS database and made available on the NDMAS Web portal (http://ndmas.inl.gov). AGR-2 thermal/neutronics simulation data are in-process, and AGR-2 PIE has not yet begun. ATR operating conditions data, including lobe powers, control cylinder positions, neck shim positions, and control rod positions, are stored in the NDMAS database and presented on the NDMAS Web portal to help interpret AGR irradiation monitoring data.

\subsection{Overview OF NDMAS Data Qualification}

NDMAS roles and responsibilities regarding data qualification are provided in two documents: Very High Temperature Reactor Program Data Management and Analysis Plan (PLN-2709) and Data Qualification (MCP-2691).

Some of the primary tasks performed by NDMAS related to data qualification are:

- Archiving submitted data in native file format on a secure $\mathrm{SAS} \AA$ server under version control (using the Subversion client, Tortoise SVN).

- Processing the data into standardized electronic data sets, storing the data in a secure electronic database compliant with the VHTR and NGNP quality plans (PLN-2690, PLN-1485), and testing the data to ensure accuracy. NDMAS is currently using SAS ${ }^{\circledR}$ Enterprise Guide and a secure Microsoft Structured Query Language (SQL) server (the "Vault") for these purposes.

- Analyzing irradiation monitoring data to identify possible data anomalies using various SAS® statistical tools such as range testing, control charts, correlation analyses, and regression analyses. These results are included in data qualification reports (such as this one) that are considered by the DRC in their determination of final data Qualification State (see below).

- Documenting the receipt of QA-approved data reports (e.g., ECARs) for FPMS and fuel fabrication data, which provide the basis for their data qualification status.

- Providing secure Web access to the data (http://ndmas.inl.gov), information on the data qualification status, and requested data analyses to end users, including external research partners. Starting with AGR-2, this includes secure limited data access to external research partners in France and South Africa.

All the AGR-2 data currently being collected at INL are considered to be Type A-data obtained within an NQA-1 QA program that must meet specific requirements for data collection with independent verification that those requirements were met (MCP-2691). The final results of this process are one of three data Qualification States applied to each data record:

- Qualified. Independent verification documents that the data meet the requirements for a specific end use as defined in a data collection plan, and the data were collected within an NQA-1 or equivalent QA program. Any nonconformances are concluded to not affect the useability of the data.

- Trend. Independent verification identifies minor flaws or gaps in meeting requirements for data use. Even so, the data still provide information that can be used by the program. Data were collected within an NQA-1 or equivalent QA program. 
- Failed. Independent verification identifies major flaws in meeting data collection requirements. Data do not provide information about the system or object. Data are not useable by the program.

While the data is being processed by NDMAS and prior to the data receiving a final Qualification State, NDMAS sets the data Qualification State to In Process. Time-critical data, such as the fuel irradiation data, are made available on the NDMAS Web portal while In Process to facilitate near realtime monitoring of experimental results by project staff. 


\section{AGR-2 EXPERIMENT}

The primary objectives of the AGR-2 experiment are defined in the Technical Program Plan for the NGNP (PLN-3636), and a detailed description of the experiment is provided in the AGR-2 Irradiation Experiment Test Plan (PLN-3798). AGR-2 is comprised of six individual capsules, approximately 1-3/8 in. in diameter and 6 in. long, stacked on top of each other to form the test train. A leadout tube holds the experiment in position and contains and protects the gas lines and $\mathrm{TC}$ wiring extending from the test train to the reactor penetration. Each capsule contains either 12 fuelecompacts that are approximately $0.5 \mathrm{in}$. in diameter by $1 \mathrm{in}$. long or six fuel compacts that are approximately $0.5 \mathrm{in}$. in diameter by $2 \mathrm{in}$. long, depending on the specific compact design. Compacts contain approximately 3,000 fissile UCOcoated particles (assuming $32 \mathrm{Vol} \%$ particle packing), approximately 2,500 $\mathrm{UO}_{2}$ coated particles (for $2 \mathrm{in}$. long compacts assuming a 16\% packing fraction), or approximately $1,500 \mathrm{UO}_{2}$ coated particles (for $1 \mathrm{in}$. long compacts assuming a $21 \%$ packing fraction). Each capsule has independently controlled helium and neon gas flows, which have different thermal conductivities to control capsule fuel temperatures. The combined gas outlet lines transport any fission products released from the fuel compacts to the FPMS, which is capable of detecting individual particle failures. There are five TCs located in Capsule 6 and two TCs in the remaining capsules as shown in Figure 1.

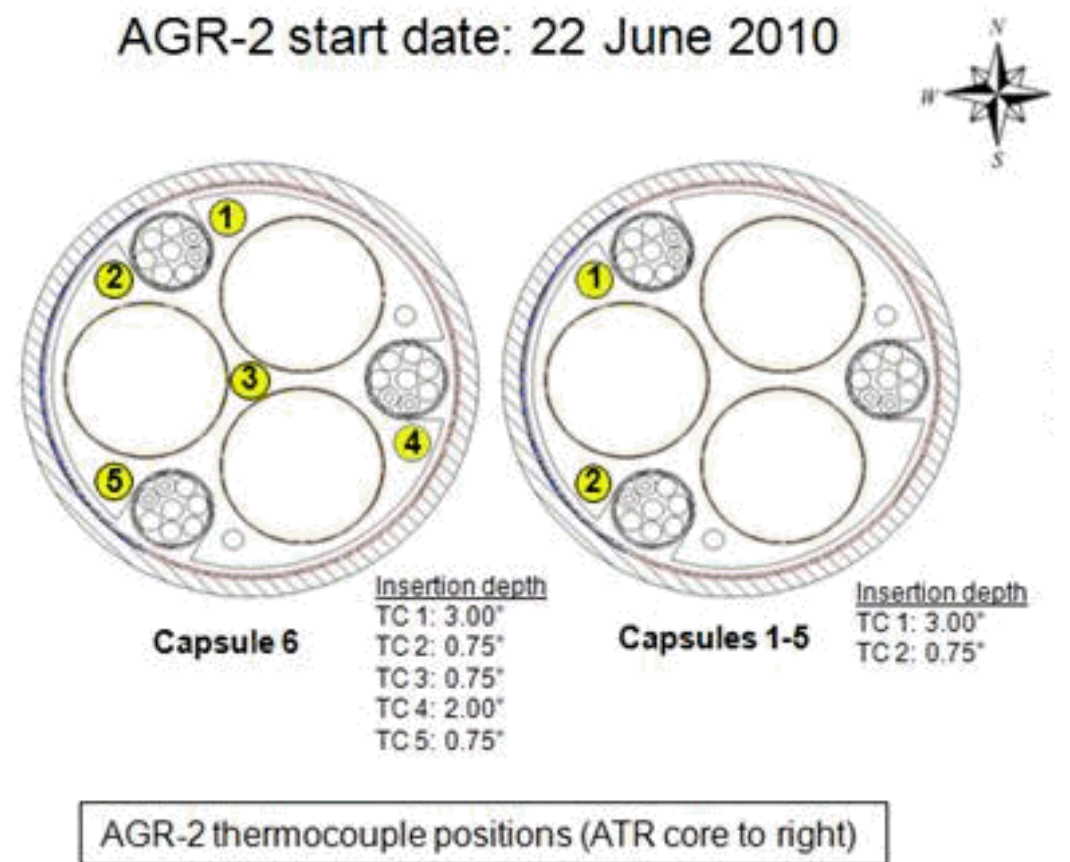

Figure 1. Radial view of the AGR-2 capsules with TC locations (yellow circles).

Each AGR-2 capsule contains only one fuel type. U.S. UCO fuel is in Capsules 2, 5 and 6; U.S. UO2 fuel is in Capsule 3; French $\mathrm{UO}_{2}$ fuel is in Capsule 1; and South African $\mathrm{UO}_{2}$ fuel is in Capsule 4. These assignments are listed in Table 1, where the capsules are numbered consecutively from the bottom (Capsule 1) to the top (Capsule 6). The French and South African capsule data are not presented or discussed in this report because of Cooperative Research and Development Agreement restrictions. 
Table 1. Fuel types in the six AGR-2 capsules (from PLN-3798).

\begin{tabular}{|lcl|}
\hline \multicolumn{1}{|c|}{ Location } & Coated Particle Composite & \multicolumn{1}{c|}{ Fuel Designation } \\
\hline Capsule 6 (top) & G73J-14-93073A & UCO \\
Capsule 5 & G73J-14-93073A & UCO \\
Capsule 4 & - & South African $\mathrm{UO}_{2}$ \\
Capsule 3 & G73H-10-93085B & $\mathrm{UO}_{2}$ \\
Capsule 2 & G73J-14-93073A & UCO \\
Capsule 1 (bottom) & - & French UO2 \\
\hline
\end{tabular}

\subsection{Requirements}

Requirements and specifications for the AGR-2 irradiation test are contained in "Requirements for the Design of the Advanced Gas Reactor Experiment AGR-2 for Irradiation in the ATR" (TFR-559), "AGR-2 Irradiation Test Specification" (SPC-1064), and "Temperature Control and Off Gas Monitoring Systems for Advanced Gas Reactor Experiment AGR-1" (TFR-248). TFR-248 applies because the AGR-2 experiment is using the same temperature control and off-gas monitoring system as AGR-1.

The requirements listed here include only those related to the measured data provided to NDMAS during the AGR-2 experiment (TC temperatures; sweep gas flow rates, pressure, and moisture content; and FPMS data). They do not include requirements related to process or instrument parameters not reported to NDMAS (e.g., sweep gas purity), requirements specifying as-installed instrument accuracy that cannot be verified during the experiment (e.g., sweep gas flow rate accuracy of $\pm 2 \%$ ), as-installed materials specifications (e.g., He-3 gas purity), or requirements that can only be evaluated by simulation modeling or PIE activities (e.g., fast neutron fluence and burnup).

\subsubsection{Requirements}

\subsubsection{Temperature}

The irradiation test condition requirements relating to temperature are summarized below (SPC-1064):

- The instantaneous peak temperature for each capsule shall be $\leq 1800^{\circ} \mathrm{C}$.

- The time average, peak temperature shall be $\leq 1400^{\circ} \mathrm{C}$ for one capsule containing $\mathrm{UCO}$ fuel, $\leq 1250^{\circ} \mathrm{C}$ for each remaining capsule containing $\mathrm{UCO}$ fuel, and $\leq 1150^{\circ} \mathrm{C}$ for each capsule containing $\mathrm{UO}_{2}$ fuel.

- The time average, volume average temperature goal should be $\geq 1150^{\circ} \mathrm{C}$ for the highest temperature capsule containing $\mathrm{UCO}$ fuel, $\geq 1000^{\circ} \mathrm{C}$ for each remaining capsule containing $\mathrm{UCO}$ fuel, and $\geq 900^{\circ} \mathrm{C}$ for each capsule containing $\mathrm{UO}_{2}$ fuel. These goals will be evaluated using simulation modeling.

\subsubsection{Sweep Gas}

The irradiation test condition requirements relating to sweep gas (helium, neon, combined outlet) are summarized below (SPC-1064, TFR-559, TFR-248):

- The moisture content of inlet sweep gas on inlet side of capsule should be $<5 \mathrm{ppm} \mathrm{H}_{2} \mathrm{O}$, measured at least once after each gas cylinder change at a dew point of $-100 \pm 2.5^{\circ} \mathrm{C}$ (SPC-1064, TFR-248).

- The moisture content of the sweep gas on the outlet side of capsule is measured at least every hour at a dew point of $-100 \pm 2.5^{\circ} \mathrm{C}$ and shall be indicated in volumetric water concentration in parts-permillion (SPC-1064). There is no published ppm limit or specification for moisture content on the 
capsule outlet side; values are monitored to ensure they do not exceed the inlet specification $(<5 \mathrm{ppm})$, which may indicate a leak (J. Maki, personal communication).

- Gas flow rates will be $\leq 50 \mathrm{sccm}$ (standard cubic centimeters per minute) at a pressure of about 15 psia or $0.103 \mathrm{MPa}$ (PLN-3798).

- Test gas mixture flow rate: 50-100 sccm (Condition 1 Normal Operations; TFR-559).

- Failure of Mass Flow Controller or Computer (Condition 2 Fault; TFR-559):

- $100 \%$ helium 0 to $100 \mathrm{sccm}$ gas flow

- $100 \%$ neon 0 to $100 \mathrm{sccm}$ gas flow

TFR-559 states, "Flow rates up to or exceeding $100 \mathrm{sccm}$ (the maximum output of the controllers) will not adversely affect the heat transfer rate from the test or invalidate the analyses."

- $\quad$ Failure of Pressure Regulator (Condition 2 Fault; TFR-559):

$100 \%$ helium Relief Valve Setting_-90 psig

$100 \%$ neon Relief Valve Setting— 90 psig.

\subsubsection{Fission Product Monitoring System}

The irradiation test condition requirements relating to the FPMS are as follows (SPC-1064):

- Able to detect every individual particle failure from each capsule, up to and including the first 250 failures, and able to identify in which capsule each failure had occurred (operation requirement in SPC-1064).

- Transit time of sweep gas $<25$ minutes from each capsule to the fission product monitoring system (operation requirement in SPC-1064).

- Continuous measurements of total radiation level of the sweep gas from each capsule (measurement requirement in SPC-1064).

- At least daily measurements of concentrations of at least $\mathrm{Kr}-85 \mathrm{~m}, \mathrm{Kr}-87, \mathrm{Kr}-88, \mathrm{Xe}-131 \mathrm{~m}, \mathrm{Xe}-133$, and $\mathrm{Xe}-135$ in the sweep gas from each capsule. Optional isotopes to also measure include $\mathrm{Kr}-89$, $\mathrm{Kr}-90, \mathrm{Xe}-135 \mathrm{~m}, \mathrm{Xe-137}$, Xe-138, and Xe-139 (measurement requirement in SPC-1064).

\subsubsection{Quality Assurance}

The AGR-2 irradiation experiment was conducted within an NQA-1 compliant QA program as implemented in the Very High Temperature Gas Reactor Technology Development Office Quality Assurance Program Plan (PLN-2690) and the Quality Assurance Program Plan for the Next Generation Nuclear Plant Project (PLN-2021). Additional details on NQA-1conformance are given in Section 4.

\subsubsection{Data Qualification}

All electronically recorded Type $A$ data are to be validated and qualified to confirm conformance with data collection requirements. For the irradiation monitoring data streams, this includes the following types of data for each capsule:

- TC temperatures (two in each capsule, except for Capsule 6, which has five)

- Sweep gas (helium, neon, outlet) measurements (mass flow rates, pressure, and moisture content)

- FPMS krypton and xenon radionuclide release rates and associated error.

- $\quad$ FPMS R/Bs and associated error for krypton and xenon radionuclides. 


\subsection{Experiment and Data Structure}

The design of the NDMAS database structure was based on a hierarchy of Experiment to Data stream to Data package to Data element. This section expands on this hierarchy by explaining these four levels and the types of information collected for them.

\subsubsection{Data Packages}

TC temperatures and sweep gas data (neon flow, helium flow, outlet flow, inlet pressure, outlet moisture) for each capsule and the leadout are currently received by NDMAS approximately once per week. Each batch of data received is termed a data package and consists of seven comma-separated values (csv) text files (one for each of the six capsules plus leadout). These files include the following data which are captured into the NDMAS database:

1. Inlet pressure (tag name, AGR1PIINx)

2. Outlet flow (tag name, AGR1FIOUTx)

3. Outlet moisture (tag name, AGR1MIOUTx)

4. Neon flow rate (tag name, ITVNE1FINESHF1x)

5. Helium flow rate (tag name, ITVHE1FINESHF1x)

6. TC temperatures (tag name, AGR1TIxy, $[\mathrm{x}=$ capsule no., $\mathrm{y}=\mathrm{TC}$ number in that capsule).

Each file contains date and time in the first two columns followed by response variable data in subsequent columns. Data records for the first four AGR-2 reactor cycles reported herein were provided as 10-minute averages. The files were placed on the $\backslash \backslash$ fsisc 1 server by ATR operations then copied to the NDMAS data archive server with operating system verification of the copy process. Once on the NDMAS server, the files were added to the subversion system (TortoiseSVN), which provides configuration control for archived files. A SAS ${ }^{\circledR}$ Enterprise Guide project was then used to read data from the csv files and convert the data into a combined AGR-2 SAS dataset.

FPMS release rate and R/B data are currently provided by FPMS technical staff to NDMAS at the end of each reactor cycle. Six capsule-specific release rate and six R/B text (txt) files are placed in the NDMAS data archive location with subversion configuration control. Data are generally provided as 8hour averages. The first three columns of data contain SPEC_ID (sample name containing the detector number, date/time, and instrument reset index), date, and time. Columns 4 and 5 contain parameters used by the FPMS technical staff to calculate radionuclide concentrations. The remaining 24 columns contain the release rates (or R/B values) and percent error for the 12 gaseous fission products. SAS ${ }^{\circledR}$ Enterprise Guide projects were then used to capture the data from the $t x t$ files into cycle-specific AGR-2 SAS ${ }^{\circledR}$ datasets.

\subsubsection{Data Elements and Components}

The NDMAS database design includes data elements and components that are used to link multiple types of measurements for the same object or tiers of objects. A data element is the data that provides information about the system or object being measured. Data elements are divided into response variables and attributes. The response variables are the numeric values, such as pressure or temperature, for a single measurement record (e.g., 10-min average gas flow rate). Attribute elements give supplemental information about the object or system being measured, such as spatial location of the measurement or units. Both response variables and attributes are associated with a component - the generic name for the object or system being measured (e.g., capsule or TC). The components and response variables established for the AGR-2 irradiation monitoring data stream are listed in Table 2. 
Table 2. NDMAS components and response variables for the AGR-2 irradiation monitoring and FPMS data.

\begin{tabular}{|c|c|c|}
\hline Component Name & $\begin{array}{l}\text { Response Variable } \\
\text { Name }\end{array}$ & Description \\
\hline \multicolumn{3}{|l|}{ Irradiation Monitoring: } \\
\hline AGR2_C1_TC $[1,2]$ & Temperature $\left({ }^{\circ} \mathrm{C}\right)$ & TC1, TC2 in Capsule 1 \\
\hline AGR2_C2_TC $[1,2]$ & Temperature $\left({ }^{\circ} \mathrm{C}\right)$ & TC1, TC2 in Capsule 2 \\
\hline AGR2_C3_TC[1,2] & Temperature $\left({ }^{\circ} \mathrm{C}\right)$ & TC1, TC2 in Capsule 3 \\
\hline AGR2_C4_TC[1,2] & Temperature $\left({ }^{\circ} \mathrm{C}\right)$ & TC1, TC2 in Capsule 4 \\
\hline AGR2_C5_TC[1,2] & Temperature $\left({ }^{\circ} \mathrm{C}\right)$ & TC1, TC2 in Capsule 5 \\
\hline AGR2_C6_TC[1-5] & Temperature $\left({ }^{\circ} \mathrm{C}\right)$ & TC1-TC5 in Capsule 6 \\
\hline AGR2_C[1-6,LO]_Moisture_Out & Humidity (ppmv) & Humidity in Capsules 1-6 and leadout \\
\hline AGR2_C[1-6, LO]_Pressure_In & Pressure (psia) & Pressure in Capsules 1-6 and leadout \\
\hline AGR2_C[1-6, LO]_Q_He_In & Q_He (sccm) & Helium flow to Capsules $1-6$ and leadout \\
\hline AGR2_C[1-6, LO]_Q_Ne_In & Q_Ne (sccm) & Neon gas flow to Capsules $1-6$ and leadout \\
\hline AGR2_C[1-6]_Q_Mix_Out ${ }^{\mathrm{a}}$ & $\begin{array}{l}\text { Q_Total }(\mathrm{sccm}) \\
{\left[\mathrm{Q} \_ \text {Mix_Out] }\right.}\end{array}$ & Gas outflow from Capsules $1-6$ \\
\hline \multicolumn{3}{|l|}{ FPMS: } \\
\hline AGR2 Capsule [1-6] & $\mathrm{Kr} \_[\mathrm{A}] \_\operatorname{Rel}($ atoms $/ \mathrm{s})$ & $\begin{array}{l}\text { Release rate for five krypton isotopes } \\
(\mathrm{A}=85 \mathrm{~m}, 87,88,89,90) \text { for each capsule }\end{array}$ \\
\hline AGR2 Capsule [1-6] & $\mathrm{Kr}[\mathrm{A}] \_$Rat (unitless) & $\mathrm{R} / \mathrm{B}$ for five krypton isotopes \\
\hline AGR2 Capsule [1-6] & $\mathrm{Xe} \_[\mathrm{A}] \_\mathrm{Rel}$ (atoms/s) & $\begin{array}{l}\text { Release rate for seven xenon isotopes } \\
(\mathrm{A}=131 \mathrm{~m}, 133,135,135 \mathrm{~m}, 137,138,139)\end{array}$ \\
\hline AGR2 Capsule [1-6] & Xe_[A]_Rat (unitless) & $\mathrm{R} / \mathrm{B}$ for seven xenon isotopes \\
\hline AGR2 Capsule [1-6] & $\left.\mathrm{Kr} \_\mathrm{A}\right] \_\operatorname{Err}(\%)$ & Release rate error for five krypton isotopes \\
\hline AGR2 Capsule [1-6] & $\mathrm{Kr} \_[\mathrm{A}] \_\mathrm{REr}(\%)$ & $\mathrm{R} / \mathrm{B}$ error for five krypton isotopes \\
\hline AGR2 Capsule [1-6] & $\mathrm{Xe} \_[\mathrm{A}] \_\operatorname{Err}(\%)$ & Release rate error for seven xenon isotopes \\
\hline AGR2 Capsule [1-6] & $\mathrm{Xe} \_[\mathrm{A}] \_\mathrm{REr}(\%)$ & $\mathrm{R} / \mathrm{B}$ error for seven xenon isotopes \\
\hline
\end{tabular}




\section{DATA PROCESSING AND TESTING}

NDMAS provides a controlled and secure electronic data storage environment, supports data qualification, identifies the qualification status of data, provides data analysis and modeling products, and makes data available for use by the program (PLN-2709). The data delivery portal (http://ndmas.inl.gov) is Web based so both internal and external NGNP Project participants can access the system and review the data, obtain analysis results (including statistics and graphics), create slide presentations, and download data. By performing these roles, the NDMAS assures the correct data are used by the project and data of known quality are available to support future licensing. Figure 2 provides a summary of the stages of data processing within NDMAS.

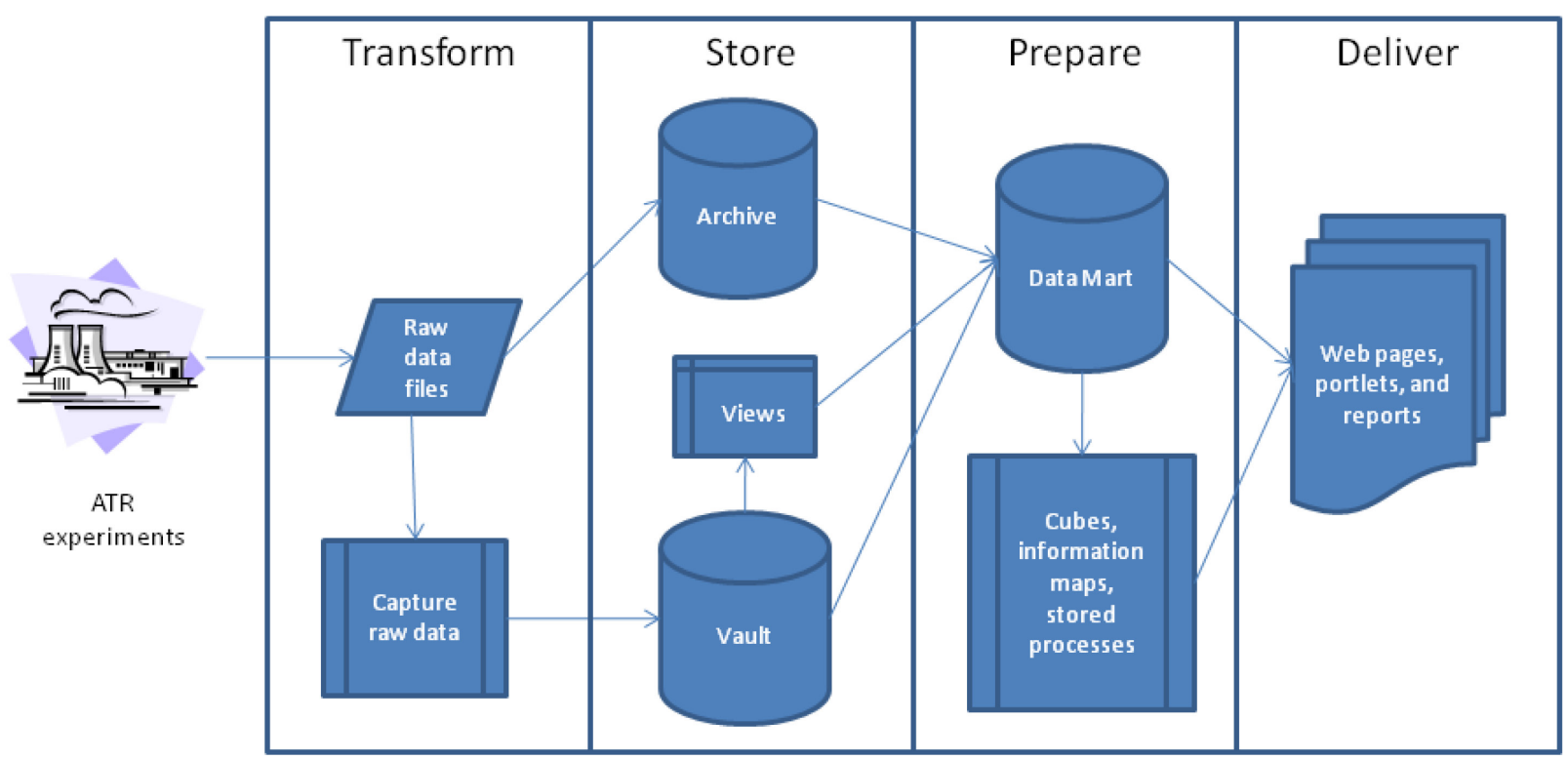

Figure 2. Stages of data processing in NDMAS.

\subsection{Data Capture}

Data capture involves using a SAS ${ }^{\circledR}$ Enterprise Guide project to read native (csv or txt) data files stored on project servers, conversion of these data into standardized SAS datasets, and insertion (appending) of these data to the NDMAS Microsoft SQL ${ }^{\circledR} 2008$ database (the "vault"). Enterprise Guide processing includes conversion of local date/time values (supplied by data generators) to mountain standard time, unit conversions, and removal of duplicate data records. When data are first appended to the vault, they are assigned a Data_State_ID flag of 1, indicating the data are "Raw" and have not yet been tested or qualified.

Data capture to the vault is verified by manually comparing vault output to the original data in the native files and by using an automated SAS comparison routine (Proc Compare) to confirm that the vault input data is identical to the vault output data. If errors are detected in the capture process, the process is reviewed to identify the source of the error, and corrections are made. It may be necessary to delete some or all of the captured records from the database and repeat the process. In other cases, the database can be corrected. Once the capture of the data is verified, the Data_State_ID is changed from 1 (Raw) to 3 (Capture Passed). 


\subsection{Testing for Data Anomalies}

After vault capture, NDMAS runs a number of tests for temperature and sweep gas irradiation monitoring data to identify potential anomalies (Table 3 ). Anomalies are data with values outside the range of expected behaviors. Some of these may reflect bad data (e.g., as a result of instrument failure), but some may reflect transient events that produced real data outside of normal ranges. The anomalies are reviewed as part of the data qualification process. This section discusses these anomaly tests, the basis for the tests, and presents the test results. Qualification decisions based on the results of these tests are presented in Section 4.

For quality purposes, NDMAS does not perform anomaly testing for FPMS data, although data analysis (e.g., regressions of R/B data with temperature) by NDMAS may be performed, as was done for AGR-1. Data quality for this data stream is documented in an ECAR, which is currently submitted by FPMS staff after each reactor cycle. When a QA-approved ECAR is received by NDMAS, a certification test is recorded in the vault for that data package, and the qualification status of the data is set to Qualified. If the FPMS data transmittal and its associated ECAR are designated as Preliminary data (as is currently the practice), it is assumed that this qualification status is subject to change if revisions to the data and revised ECARs are subsequently submitted by the FPMS staff (as was done for AGR-1).

Table 3. NDMAS tests performed for AGR-2 irradiation monitoring data.

\begin{tabular}{|c|c|c|c|}
\hline Test Type & Test Name & Test Description & Applied to \\
\hline \multirow[t]{2}{*}{ Accuracy } & Range & $\begin{array}{l}\text { Compares response values to anticipated/nominal } \\
\text { ranges for the experiment. Identifies anomalous } \\
\text { values that fall outside the expected range. }\end{array}$ & $\begin{array}{l}\text { Temperature, gas } \\
\text { flow, gas pressure, } \\
\text { humidity }\end{array}$ \\
\hline & Instrument Failure & $\begin{array}{l}\text { Used to fail data collected from an instrument } \\
\text { that has been deemed to no longer be providing } \\
\text { reliable data. }\end{array}$ & $\begin{array}{l}\text { All response } \\
\text { variables as needed }\end{array}$ \\
\hline Analysis & $\begin{array}{l}\text { TC Difference } \\
\text { Control Charts }\end{array}$ & $\begin{array}{l}\text { Anomaly testing for TC drift: The temperature } \\
\text { difference between TCs in the same capsule } \\
\text { should be similar over time. Trends and } \\
\text { discontinuities in the data suggest that one of the } \\
\text { TCs is drifting. }\end{array}$ & All TCs \\
\hline Analysis & $\begin{array}{l}\text { TC Spatial } \\
\text { Correlations }\end{array}$ & $\begin{array}{l}\text { Anomaly testing for TC junction failure: A TC } \\
\text { should be most highly correlated with one in the } \\
\text { same (or nearby) capsule. Higher correlation with } \\
\text { a distant TCs suggests a TC junction failure. }\end{array}$ & All TCs \\
\hline Certification & $\begin{array}{l}\text { Data Qualification } \\
\text { Certification }\end{array}$ & $\begin{array}{l}\text { Receipt by NDMAS of a QA-approved data } \\
\text { report (e.g., ECAR) }\end{array}$ & FPMS data \\
\hline
\end{tabular}

\subsubsection{Irradiation Monitoring Range Tests}

Range tests evaluate whether instrument readings fall within an expected range of values, given what is known about experimental operating conditions or instrument range specifications. Range tests are used as a simple screening tool to identify data records that could potentially be bad, or they can be used to identify and reexamine extreme, but valid, data. Range tests are currently only applied to the TC and sweep gas data that NDMAS receives. The range test limits selected for these response variables are listed in Table 4. 
Table 4. Range test limits applied to AGR-2 irradiation monitoring data (see Section 1.1.1 Requirements).

\begin{tabular}{|c|c|c|}
\hline $\begin{array}{l}\text { Response } \\
\text { Variable }\end{array}$ & $\begin{array}{l}\text { Range Test } \\
\text { Limits }\end{array}$ & Comments \\
\hline $\begin{array}{l}\text { Capsule TC } \\
\text { Temperature }\end{array}$ & 0 to $1400^{\circ} \mathrm{C}$ & $\begin{array}{l}\text { For Capsules } 1-6 \text {. Based on the capsule time average, peak fuel } \\
\text { temperature requirement. TC temperatures are expected to be lower } \\
\text { than this fuel temperature requirement, which can only be } \\
\text { evaluated by simulated modeling. }\end{array}$ \\
\hline $\begin{array}{l}\text { helium } / \text { neon inlet } \\
\text { gas flow }\end{array}$ & 0 to $50 \mathrm{sccm}$ & $\begin{array}{l}\text { For Capsules } 1-6 \text { and leadout. Based on nominal flow rates } \\
\text { specified in TFR-248. }\end{array}$ \\
\hline $\begin{array}{l}\text { Capsule gas } \\
\text { mixture outlet flow }\end{array}$ & 0 to $100 \mathrm{sccm}$ & $\begin{array}{l}\text { For Capsules 1-6. Maximum test gas mixture flow rate specified in } \\
\text { TFR-559 (Condition } 1 \text { Normal Operations) and maximum MFC } \\
\text { rating given in TFR-248. }\end{array}$ \\
\hline $\begin{array}{l}\text { Gas pressure- } \\
\text { capsule inlet }\end{array}$ & 0 to 90 psia & $\begin{array}{l}\text { For Capsules } 1-6 \text { and leadout. Maximum pressure set to pressure } \\
\text { relief valve setting specified in TFR-559. }\end{array}$ \\
\hline $\begin{array}{l}\text { Moisture-capsule } \\
\text { outlet }\end{array}$ & 0 to $5 \mathrm{ppm}$ & $\begin{array}{l}\text { For Capsules } 1-6 \text { and leadout. No published limit for capsule outlet } \\
\text { moisture level. Limit is set to the gas inlet specification in SPC- } \\
1064 \text {, the exceedance of which may indicate a leak. }\end{array}$ \\
\hline
\end{tabular}

\subsubsection{Temperatures}

Four temperature measurements fell well outside the range test criteria $\left(0-1400^{\circ} \mathrm{C}\right)$ as shown in Table 5. The magnitude of these values indicates that they do not represent actual temperatures in the AGR-2 capsules and are likely due to a data acquisition error. All of these values are flagged as Failed data.

Table 5. Temperature values $\left({ }^{\circ} \mathrm{C}\right)$ that exceeded test range criteria.

\begin{tabular}{|cccc|}
\hline Data_Package_ID & Value & Component Name & Standard Date:Time \\
\hline 123 & $-161,062$ & C6_TC1 & 24Jun2010:13:00 \\
126 & $-321,431$ & C2_TC2 & 01Jul2010:11:50 \\
166 & $-168,168.60$ & C2_TC1 & 09Nov2010:14:30 \\
193 & $-1,999,966$ & C5_TC1 & 13Apr2011:07:38 \\
\hline
\end{tabular}

\subsubsection{Gas Flow Rates}

Range tests for gas flow rates identified 359 data records where the helium inlet flow rates (Q_He_In) exceeded the upper range criteria of $50 \mathrm{sccm}$ as shown in Table 6 . These exceedances, which generally ranged from 50 to $100 \mathrm{sccm}$, all occurred over short time periods (5 min to 3 hours) during outages and are attributed to the operational need to flood the experiment with excess helium to reduce capsule temperatures at the start of an outage. They are therefore considered to be valid (Qualified) data.

Range tests also identified 99 records where the outlet flow rates (Q_Mix_Out) were slightly negative $(-0.002$ to $-0.007 \mathrm{sccm})$. These values occurred during periods when both the neon and helium inlet gas flows were reduced to zero for gas-line testing. These records are considered to be valid (Qualified) because the maximum error from zero is less than $1 \%$, which is less than the $2 \%$ accuracy criteria for the mass flow controllers given in TFR-248 and SPC-1064. 
Table 6. Gas flow rate data (5-10 min records) that exceeded range test criteria.

\begin{tabular}{|c|c|c|c|c|c|}
\hline $\begin{array}{c}\text { Data } \\
\text { Package }\end{array}$ & $\begin{array}{l}\text { Data Range } \\
(\text { sccm) }\end{array}$ & $\begin{array}{c}\text { No. of } \\
\text { Records }\end{array}$ & $\begin{array}{c}\text { Component } \\
\text { Name }\end{array}$ & Date & Reactor State \\
\hline 138 & 50.4 to 65 & 5 & C2_Q_He_In & 23Jul2010 & $\begin{array}{l}\text { Unplanned outage } \\
147 \mathrm{~A}\end{array}$ \\
\hline 158 & -0.002 to -0.0045 & 17 & C3_Q_Mix_Out & $040 c t 2010$ & Full power $148 \mathrm{~A}$ \\
\hline \multirow[t]{8}{*}{160} & - & 7 & C1_Q_He_In & 29 Oct -5 Nov 2010 & Outage \\
\hline & 62.5 to 100.0 & 7 & C2_Q_He_In & 29 Oct -5 Nov 2010 & 148B \\
\hline & 68.4 to 100.2 & 8 & C3_Q_He_In & 29 Oct -5 Nov 2010 & “ \\
\hline & -0.002 to -0.007 & 82 & C3_Q_Mix_Out & 02 Nov -5 Nov 2010 & “ \\
\hline & - & 7 & C4_Q_He_In & 29Oct -5Nov2010 & “ \\
\hline & 54.4 to 100.1 & 9 & C5_Q_He_In & 29 Oct -5 Nov 2010 & “" \\
\hline & 58.9 to 104.8 & 9 & C6_Q_He_In & 29 Oct -5 Nov 2010 & “ \\
\hline & 68.4 to 100.1 & 7 & LO_Q_He_In & 29 Oct -5 Nov 2010 & “ \\
\hline \multirow[t]{7}{*}{166} & - & 25 & C1_Q_He_In & 17 Nov2010 & Power up \\
\hline & 53.2 to 100.0 & 25 & C2_Q_He_In & 17 Nov2010 & $148 \mathrm{~B}$ \\
\hline & 51.8 to 100.2 & 26 & C3_Q_He_In & 17 Nov2010 & “ \\
\hline & -- & 26 & C4_Q_He_In & 17 Nov2010 & “" \\
\hline & 55.7 to 100.1 & 26 & C5_Q_He_In & 17 Nov2010 & “ \\
\hline & 59.7 to 104.4 & 26 & C6_Q_He_In & 17 Nov2010 & “" \\
\hline & 80.4 to 100.1 & 24 & LO_Q_He_In & 17 Nov2010 & “ \\
\hline \multirow[t]{7}{*}{178} & - & 28 & C1_Q_He_In & 8Jan -10Jan2011 & Outage \\
\hline & 73.5 to 100.0 & 28 & C2_Q_He_In & 8Jan -10Jan2011 & $149 \mathrm{~A}$ \\
\hline & 74.2 to 100.2 & 28 & C3_Q_He_In & 8Jan -10Jan2011 & “ \\
\hline & - & 28 & C4_Q_He_In & 8Jan -10Jan2011 & “" \\
\hline & 75.8 to 100.1 & 28 & C5_Q_He_In & 8Jan -10Jan2011 & “ \\
\hline & 74.1 to 104.8 & 28 & C6_Q_He_In & 8Jan -10Jan2011 & “ \\
\hline & 96.7 to 100.1 & 41 & LO_Q_He_In & 8Jan -10Jan2011 & “ \\
\hline \multirow[t]{7}{*}{216} & - & 14 & C1_Q_He_In & 21May2011 & Power down \\
\hline & 67.2 to 99.9 & 14 & C2_Q_He_In & 21May2011 & 149A \\
\hline & 68.9 to 100.1 & 14 & C3_Q_He_In & 21May2011 & " \\
\hline & - & 14 & C4_Q_He_In & 21May2011 & “" \\
\hline & 50.2 to 100.1 & 15 & C5_Q_He_In & 21May2011 & “" \\
\hline & 54.3 to 102.6 & 15 & C6_Q_He_In & 21May2011 & “ \\
\hline & 68.8 to 99.7 & 36 & $\mathrm{LO} \mathrm{Q} \mathrm{He}$ In & 21May2011 & “" \\
\hline
\end{tabular}

Gas flow leakage sometimes occurs from the leadout tube into the capsules, resulting in total (helium + neon) capsule outlet flow rates (Q_Mix_Out) that exceed the sum of the helium + neon inlet flow rates. The leadout tube running down the length of the AGR-2 test train contains and protects the capsule instrumentation and is pressurized with helium or neon to about 1 psig above capsule pressure by design to prevent helium/neon gas leakage between capsules (PLN-3798, TFR-248). The highest leakage 
observed occurred in Capsule 5 which was known early on in the experiment to be a "leaky" capsule (often measured at around $5 \mathrm{sccm}$ ) as shown in Figure 3. However, this leakage has been determined by the DRC to not affect gas data qualification for any of the capsules because it does not impact the accuracy of the capsule outlet gas flow measurement and is taken into account in the FPMS radionuclide release rate processing and the neon fraction calculation for the ABAQUS thermal model.

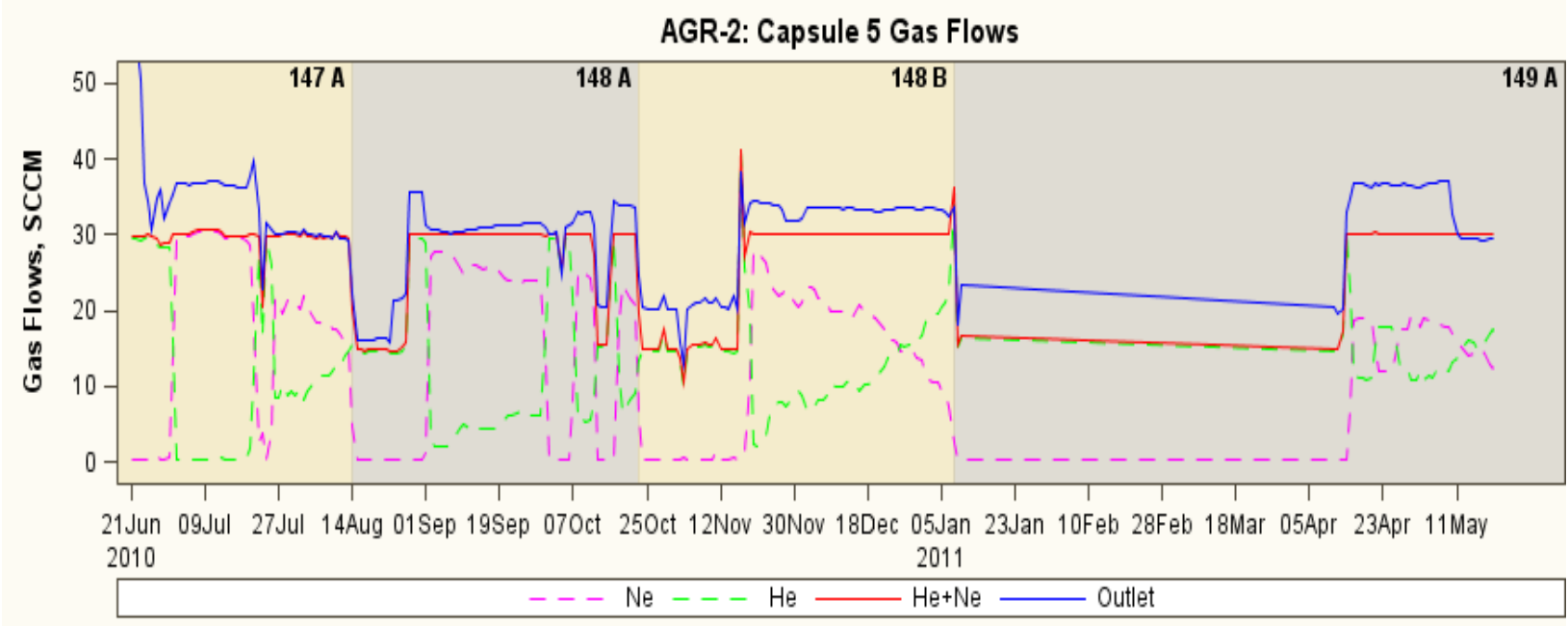

Figure 3. Leakage from the leadout into Capsule 5 is shown by the difference between the helium+neon inlet flow rate (red line) and the capsule outlet flow rate (blue line).

\subsubsection{Instrument Failure Test}

The instrument failure test visually assesses the data to determine whether the instrument has stopped responding and is currently only applied to TCs. TC failures are generally communicated to NDMAS from NGNP experiment leads. When a TC fails and the failure is verified during the data qualification (DRC) process, all future data collected from the instrument are failed.

TC 5 in Capsule 6 appears to have failed on October 12, 2010, at the start of an unplanned outage in Cycle 148A as shown in Figure 4. At this time, all of the other TCs in Capsule 6 dropped to and varied around $35^{\circ} \mathrm{C}$ while TC 5 dropped and remained fixed at exactly $41.44659^{\circ} \mathrm{C}$. After that, TC 5 never again responded to increases in reactor power (on October 17). Based on this performance history, TC 5 was assumed to have failed at 20:00 MST on October 12, and all data after that time are considered to be Failed.

TC 2 in Capsule 2 has never responded during AGR-2 irradiation and is therefore assumed to have failed during installation. All data from this TC during the AGR-2 test are considered Failed data. TC 1 failed on November 27, 2010, during reactor Cycle 148B as shown in Figure 5, leaving Capsule 2 with no functioning TCs. The last valid reading for this TC is assumed to have occurred at $1610 \mathrm{MST}$ on November 27, 2010, based on review of the raw data files. After this reading, the indicated temperature values dropped rapidly to approximately $29^{\circ} \mathrm{C}$. All data after this time are considered to be Failed.

Both TC 1 and TC 2 in Capsule 5 appear to have failed during reactor shutdown on May 21, 2010, since neither of these TCs responded at the start of Cycle 149B. The last valid readings for these TCs are assumed to have occurred at 06:00 on May 21, after which the hourly-average temperatures started to drop below $800^{\circ} \mathrm{C}$ as shown in Figure 6 . 
Thermocouple Temperatures (deg C)

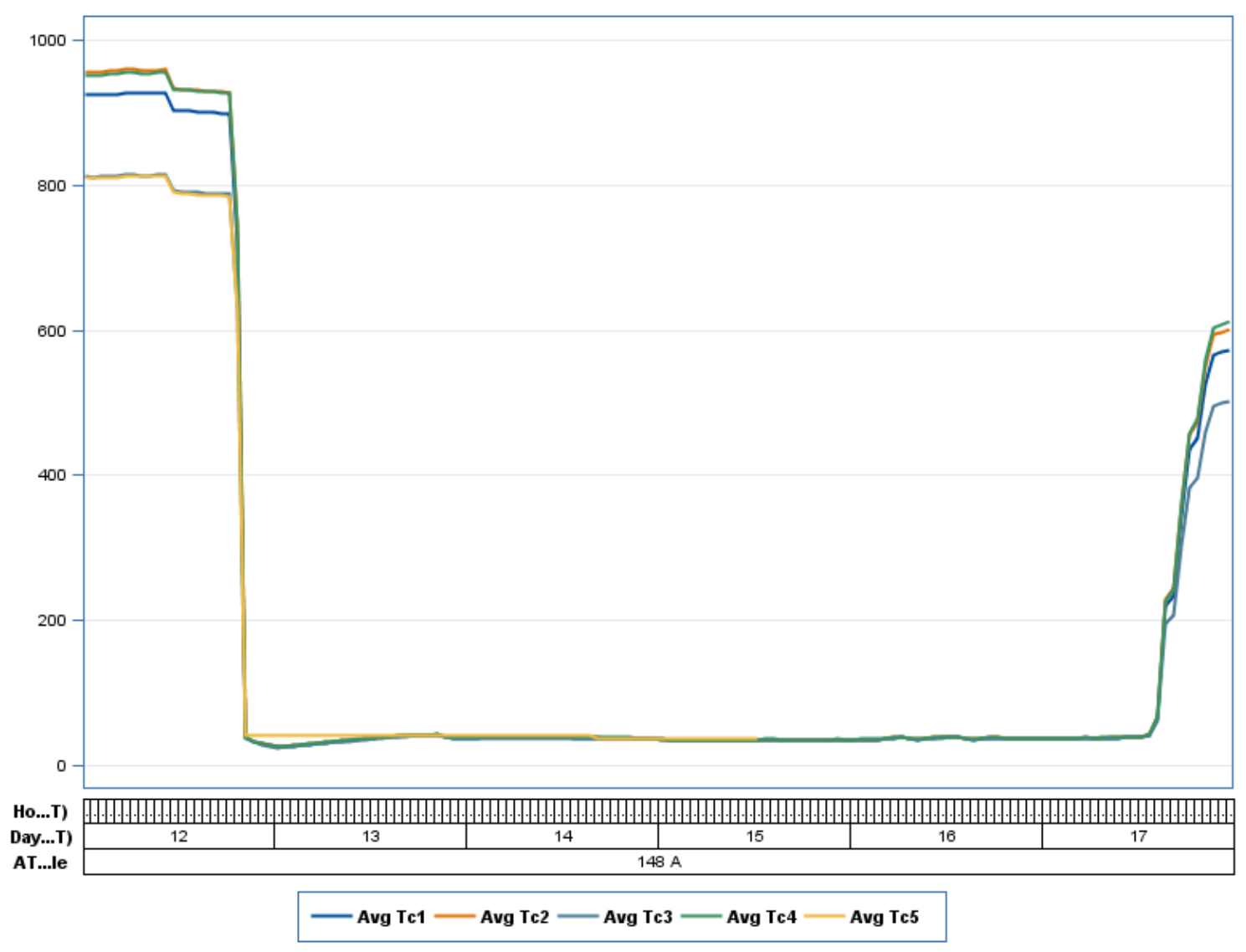

Figure 4. Failure of TC 5 in Capsule 6 occurred on October 12, 2010 during reactor Cycle 148A.

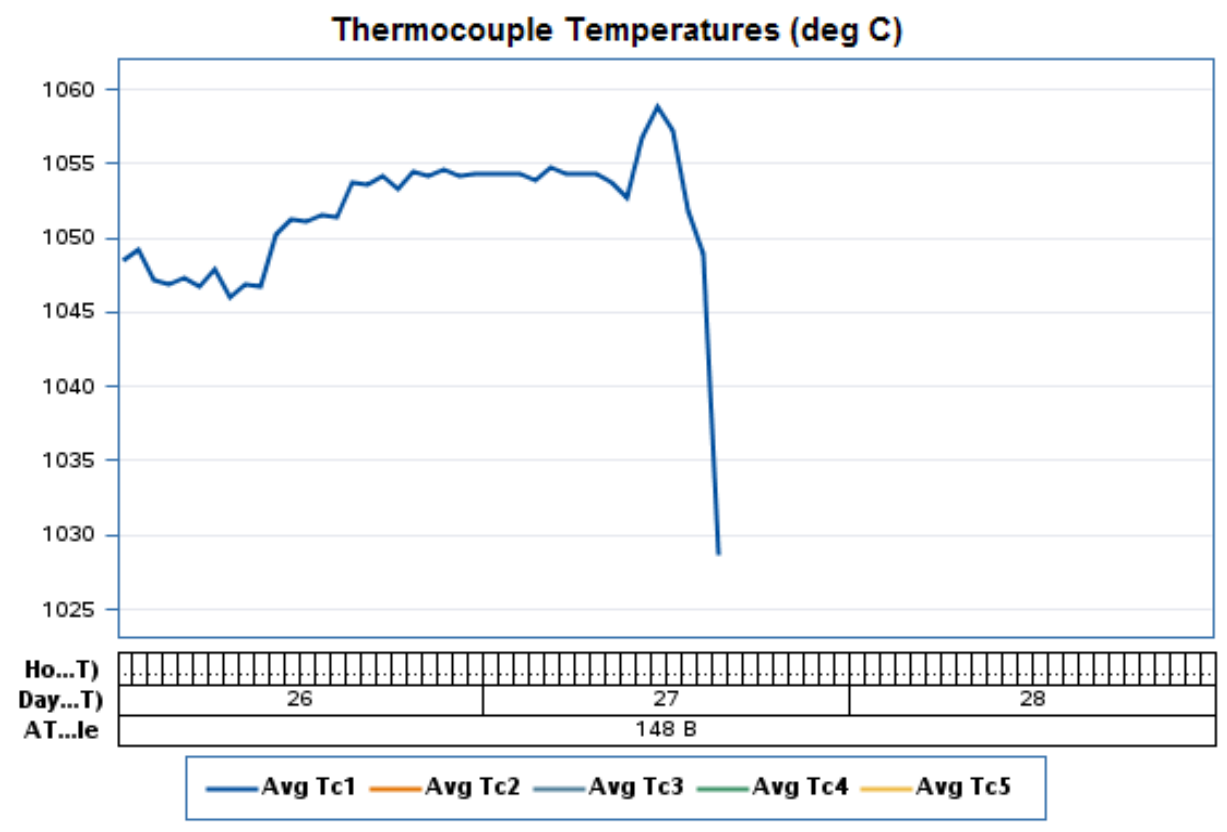

Figure 5. Failure of the remaining TC 1 in Capsule 2 occurred during reactor Cycle 148B on November 27, 2010. 


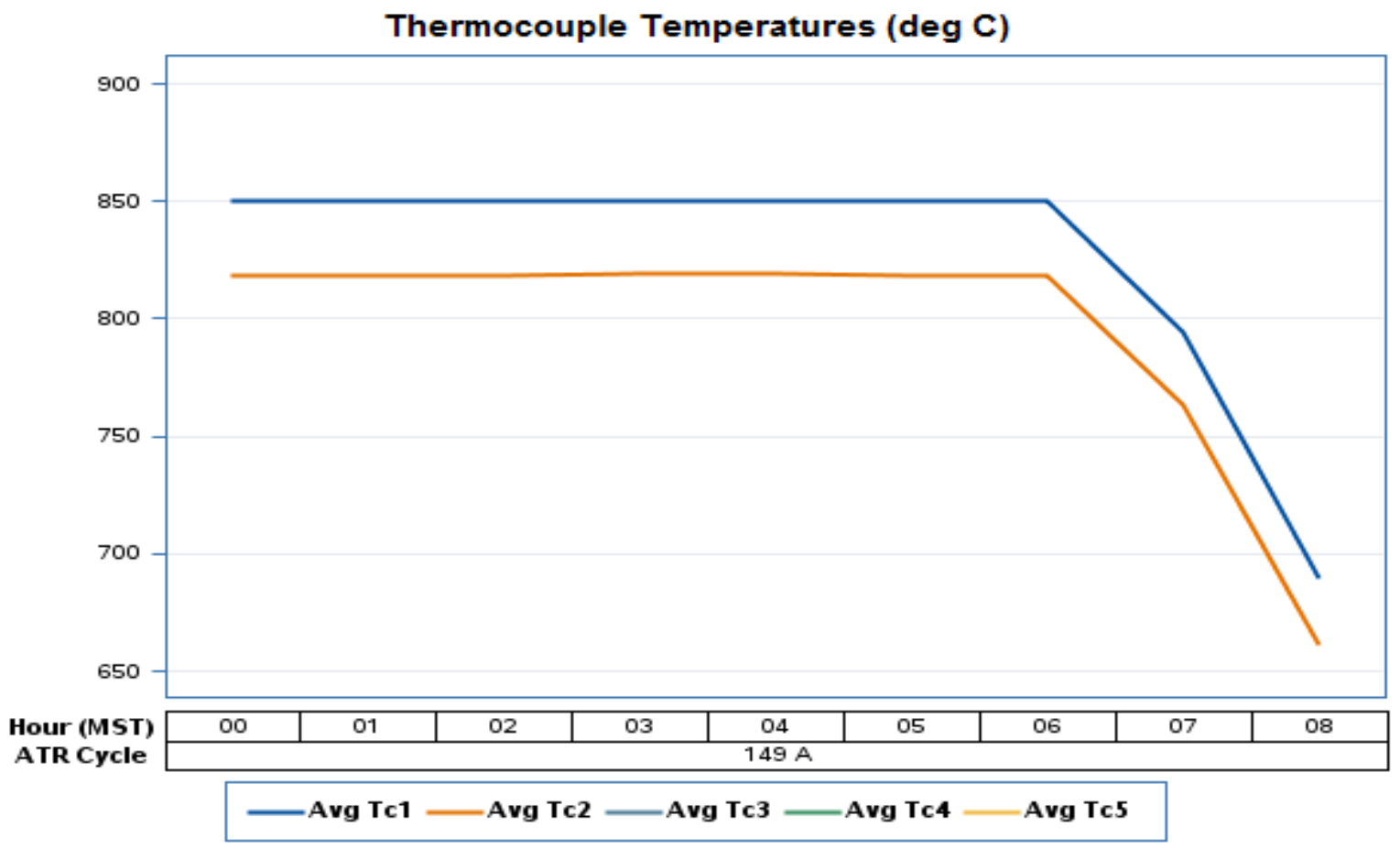

Figure 6. In Capsule 5, both TC 1 and TC 2 failed at approximately 0600 on May 21, 2011, at the conclusion of reactor Cycle 149A. Neither of these TCs responded to full power at the start of reactor Cycle 149B.

\subsubsection{Time Series Plots}

This section compares measured TC and sweep gas flow data to bounds derived from AGR-2 fuel requirements specified in SPC-1064 and TFR-559. In general, conformance to the temperature requirements can only be evaluated using thermal simulation modeling because they are based on instantaneous or peak values within any point in the fuel and on volume average temperatures in the fuel, both of which do not correspond with the averaging times (10-min) or measurement locations of the TCs. The plots provided here are for informational purposes only and to assist in interpretation of the correlation plots and control charts in the next section. Final decisions regarding whether data met requirements or specifications for the experiment will be included in an AGR-2 as-run report written after the experiment is complete.

For FPMS data, SPC-1064 specifies that the system be able to detect every individual particle failure from each capsule, up to and including the first 250 failures, and be able to identify the capsule in which failures occur. According to QA-approved ECARs from the FPMS staff, no particle failures have been observed (Section 4.1). Plots of these FPMS data are provided here for informational purposes only.

\subsubsection{Temperature Data}

Time average, peak temperature requirements for the UCO fuel (Capsules 6, 5, and 2) are $\leq 1400^{\circ} \mathrm{C}$ for one capsule and $\leq 1250^{\circ} \mathrm{C}$ for the remaining capsules. The requirement for the $\mathrm{UO}_{2}$ fuel (Capsule 3 ) is $\leq 1150^{\circ} \mathrm{C}$. In all cases, daily-average TC temperatures recorded during the first four reactor cycles of AGR-2 were less than these requirements as shown in Figure 7, although these peak temperature requirements can only be rigorously evaluated using thermal simulation modeling. This also applies to the time-averaged, volume-averaged temperature goals specified in section 2.1.1.1 
Thermocouple Temperatures $(\operatorname{deg} \mathrm{C})$

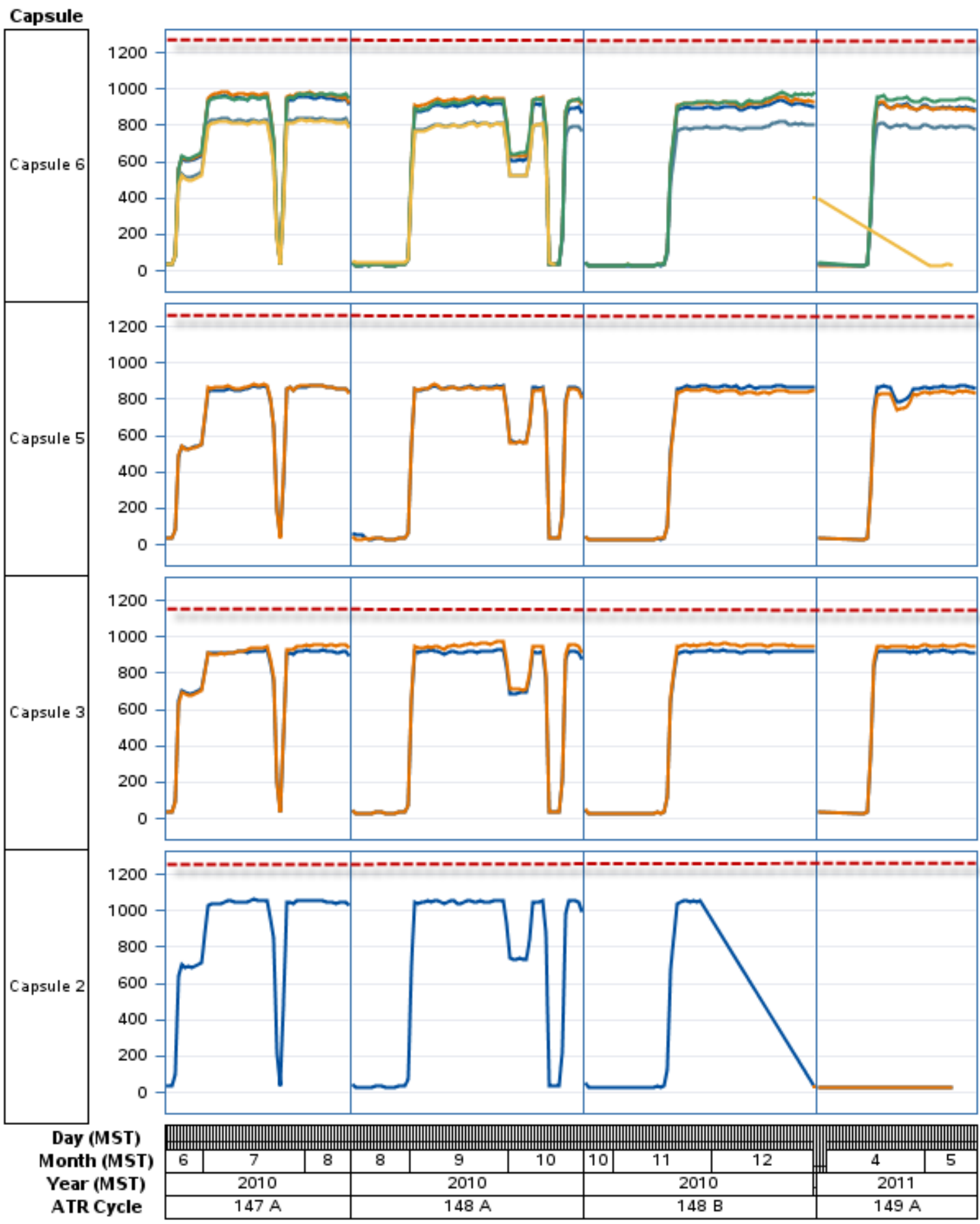

Avg Tc1 —Avg Tc2 —Avg Tc3 —Avg Tc4 Avg Tc5

Figure 7. Comparisons of daily-average $\mathrm{TC}$ temperatures with $\mathrm{UCO}$ and $\mathrm{UO}_{2}$ temperature specifications in SPC-1064 and TFR-559. 


\subsubsection{Sweep Gas Data}

Figure 8 shows the daily-average helium and neon gas flow data for the capsules, all of which are below the nominal $50 \mathrm{sccm}$ listed in the requirements (Section 2.1.1.2). Short-term (e.g., 10-min) helium flow rates sometimes exceeded $50 \mathrm{sccm}$ during outages as shown in Table 6 , but these values were generally less than the $100 \mathrm{sccm}$ flow rate specified in TFR-559: "Flow rates up to or exceeding $100 \mathrm{sccm}$ (the maximum output of the controllers) will not adversely affect the heat transfer rate from the test or invalidate the analyses."

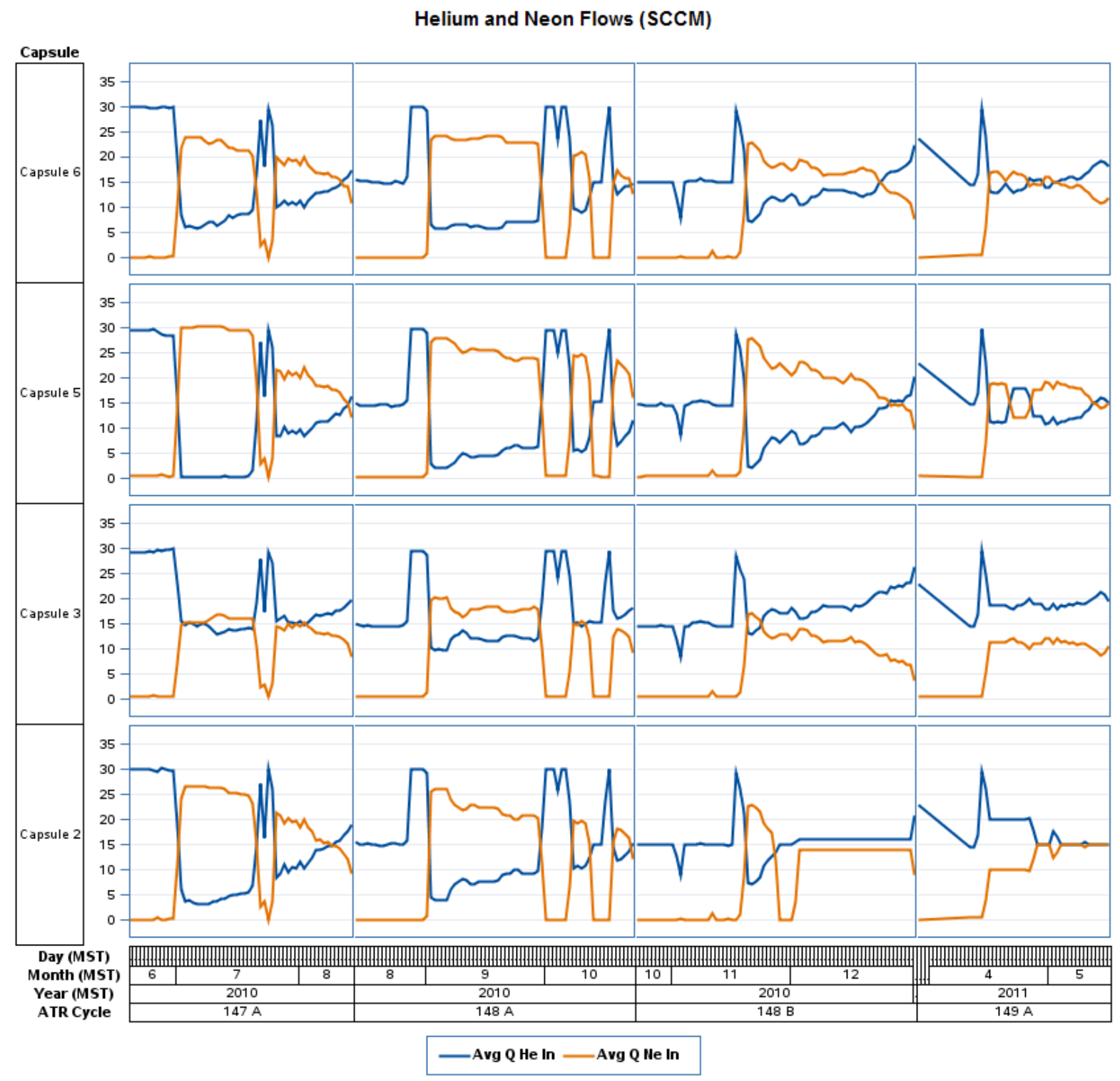

Figure 8. Daily-average gas flow rates to the capsules (sccm).

\subsubsection{FPMS Data}

Figures 9 and 10 provide plots of the fission product gaseous release rates and R/B ratios data that has been submitted to NDMAS. Detailed documentation of the FPMS methods and data quality is contained in cycle-specific ECARs (\# 1348, 1355, and 1412) submitted by the FPMS staff. The stepped decrease 
noted in capsule 2 data during cycle 148B (lower right in Figures 9 and 10) was due to an intentional 6day shutdown of neon gas flow to that capsule after the failure of the last remaining TC in that capsule on November 27, 2010 (Figure 5).

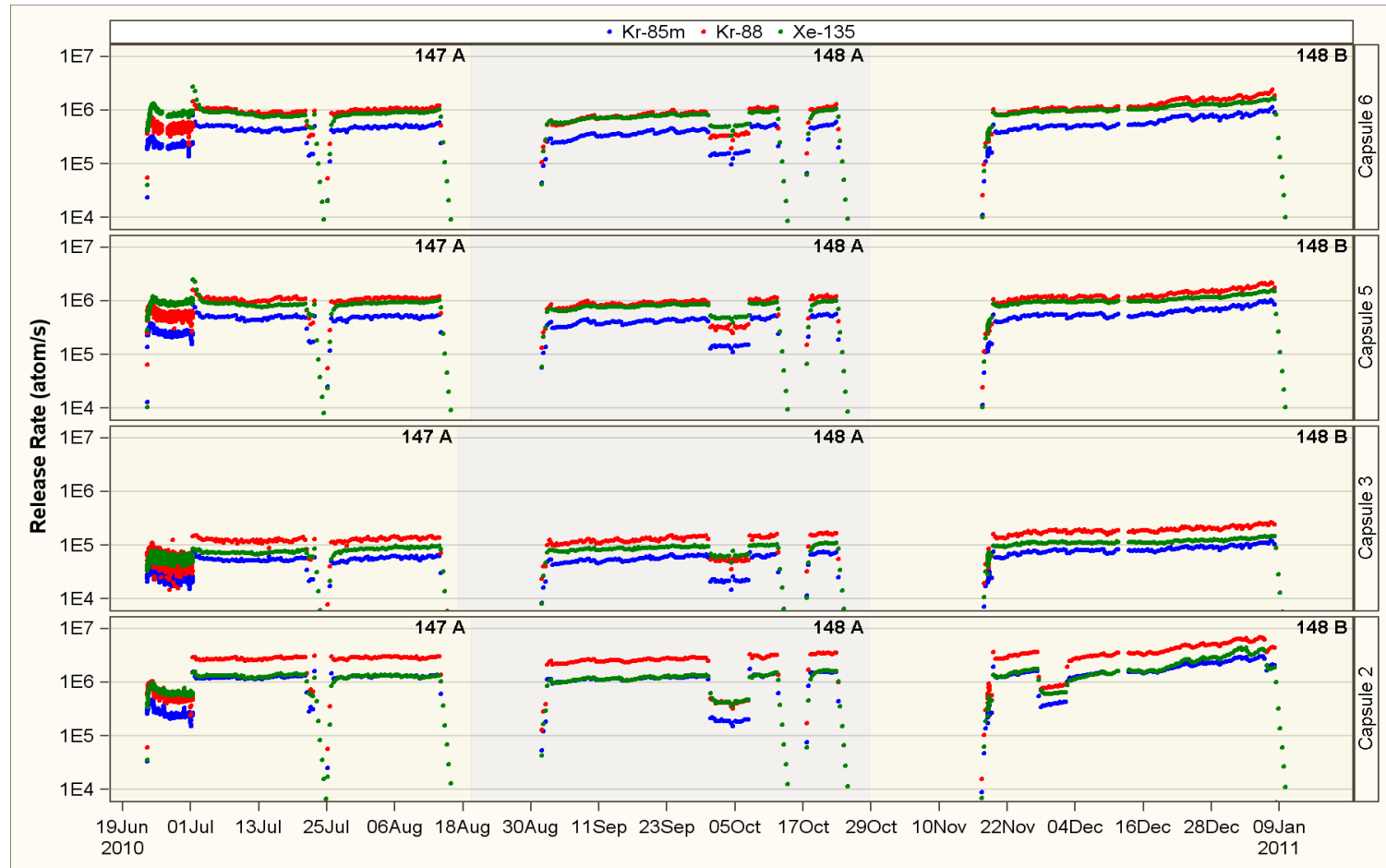

Figure 9. Fission product release rates for $\mathrm{Kr}-85 \mathrm{~m}, \mathrm{Kr}-88$, and $\mathrm{Xe}-135$.

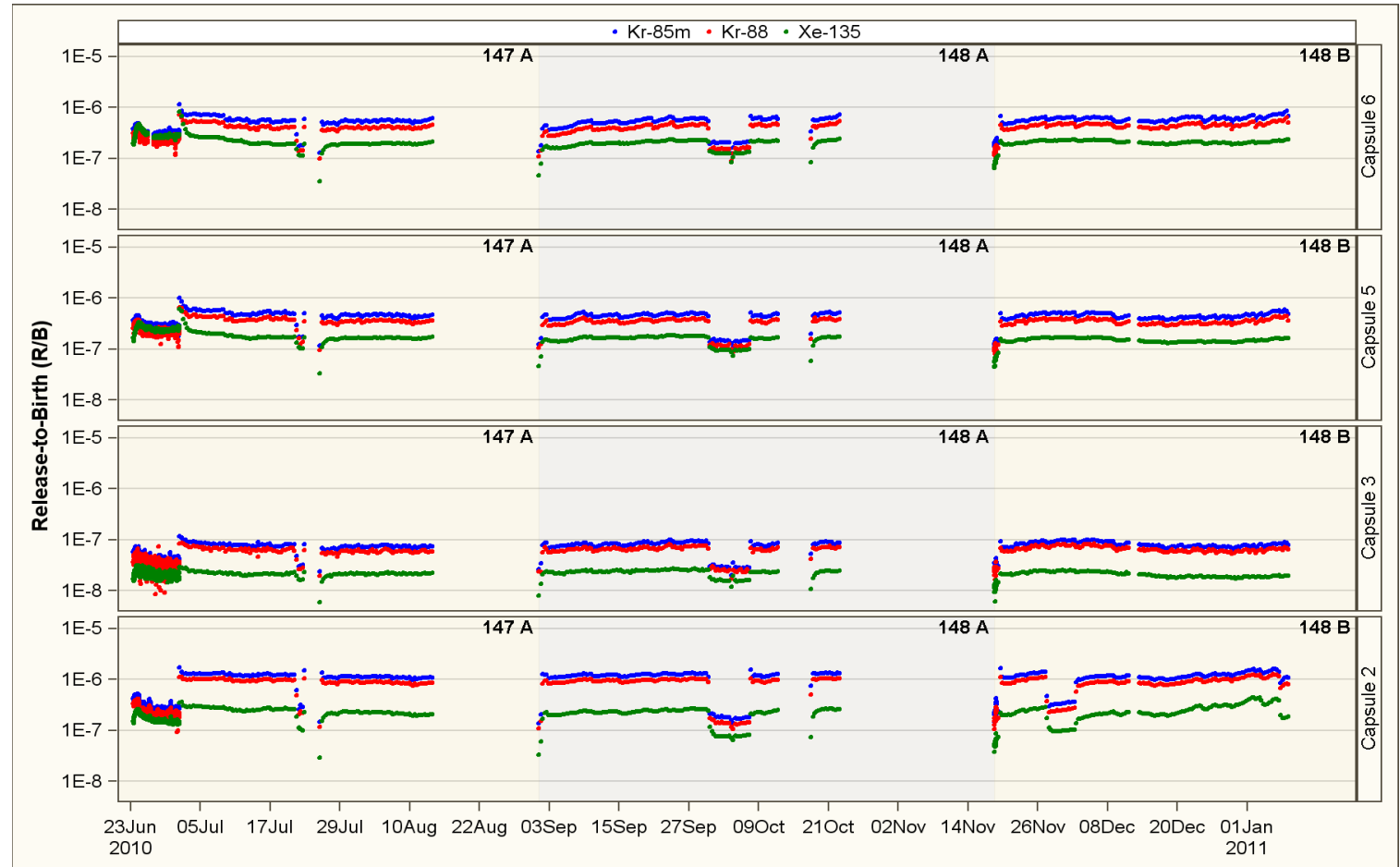

Figure 10. Fission product $\mathrm{R} / \mathrm{B}$ ratios for $\mathrm{Kr}-85 \mathrm{~m}, \mathrm{Kr}-88$, and $\mathrm{Xe}-135$. 


\subsubsection{Control Charts-TC Drift}

Control charts are one of several statistical analyses performed by NDMAS to help personnel visualize and identify unacceptable TC drift during experiment operations. The challenge for those interpreting a control chart is determining whether this drift is real and when the drift becomes unacceptable, thereby affecting the qualification state of the data.

A control chart requires an initial baseline data period, where the ranges of typical operating conditions are determined. This is followed by a monitoring period where the most recent measured data are evaluated relative to the baseline period. A control chart centerline is calculated for each capsule using the mean of the differences between TC pairs in that capsule during the baseline period. Control chart upper and lower control limits for the TC differences are then calculated as three standard deviations above and below the control chart mean difference. If the time series has a constant mean and standard deviation, $99.7 \%$ of the TC differences during the monitoring period data will fall between the upper and lower control limits.

The control chart assumption that there be a constant mean and standard deviation between the baseline and monitoring periods may not always be valid because of possible differential heating across TC pairs within a capsule as the experiment progresses. Thus, interpretation of data responses relative to control chart limits cannot be strictly defined with regard to data qualification status. Although NDMAS provides control chart results and statistical interpretations, the final determination of whether there is unacceptable TC drift is made by AGR project leads during the DRC process using multiple performance indicators, including control charts, simulated fuel temperatures, and engineering judgment.

The following subsections discuss control chart findings for capsules that were reported in monthly NGNP reports to have possible drift during the second through fourth cycles (there is no control chart for the first cycle because there is no baseline period for it). Correlation results are also provided between the TC pairs to assist in interpretation of the results. All of these plots are available on the NDMAS Web portal (http://ndmas.inl.gov) under AGR-2/Analysis/Temperatures.

\subsubsection{Control Chart Results-Capsule 3}

The control chart for Capsule 3 indicated potential drift of about $50^{\circ} \mathrm{C}$ for one $\mathrm{TC}$ during the second reactor cycle (148A) as shown in Frame 1 of Figure 11; this finding was classified as an Early Warning in October 2010. Results in the third cycle suggested that a potential unknown physical process may have caused the early drift; Cycle 4 data indicated a stable difference between the TC pairs with little or no drift.

DRC Recommendation: No failure of data indicated from control chart drift for both TCs in Capsule 3 during the first four reactor cycles.

\subsubsection{Control Chart Results-Capsule 5}

In December 2010, a gradual drift was reported for one of the TCs in Capsule 5, which started in Cycle 2 and seemed to continue into Cycle 3 as shown in Frame 1 of Figure 12. In the latter half of Cycle 3, the drift seemed to stabilize and reverse as shown in Frame 1 of Figure 13. In Cycle 4, the TC differences were stable and within control limits as shown in Figure 13.

DRC Recommendation: No failure of data indicated from control chart drift for both TCs in Capsule 5. 


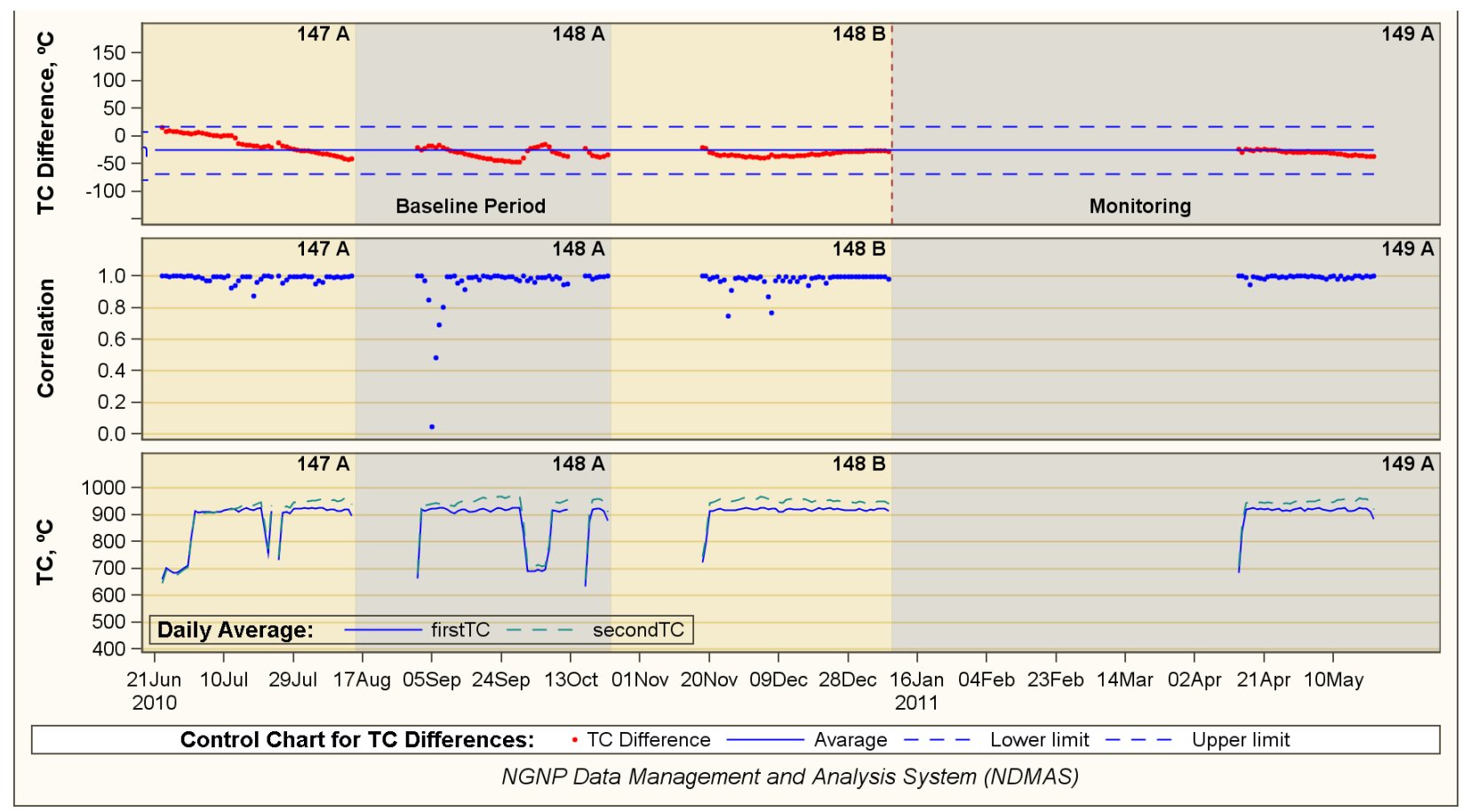

Figure 11. Drift monitoring for TC1 and TC2 in Capsule 3.

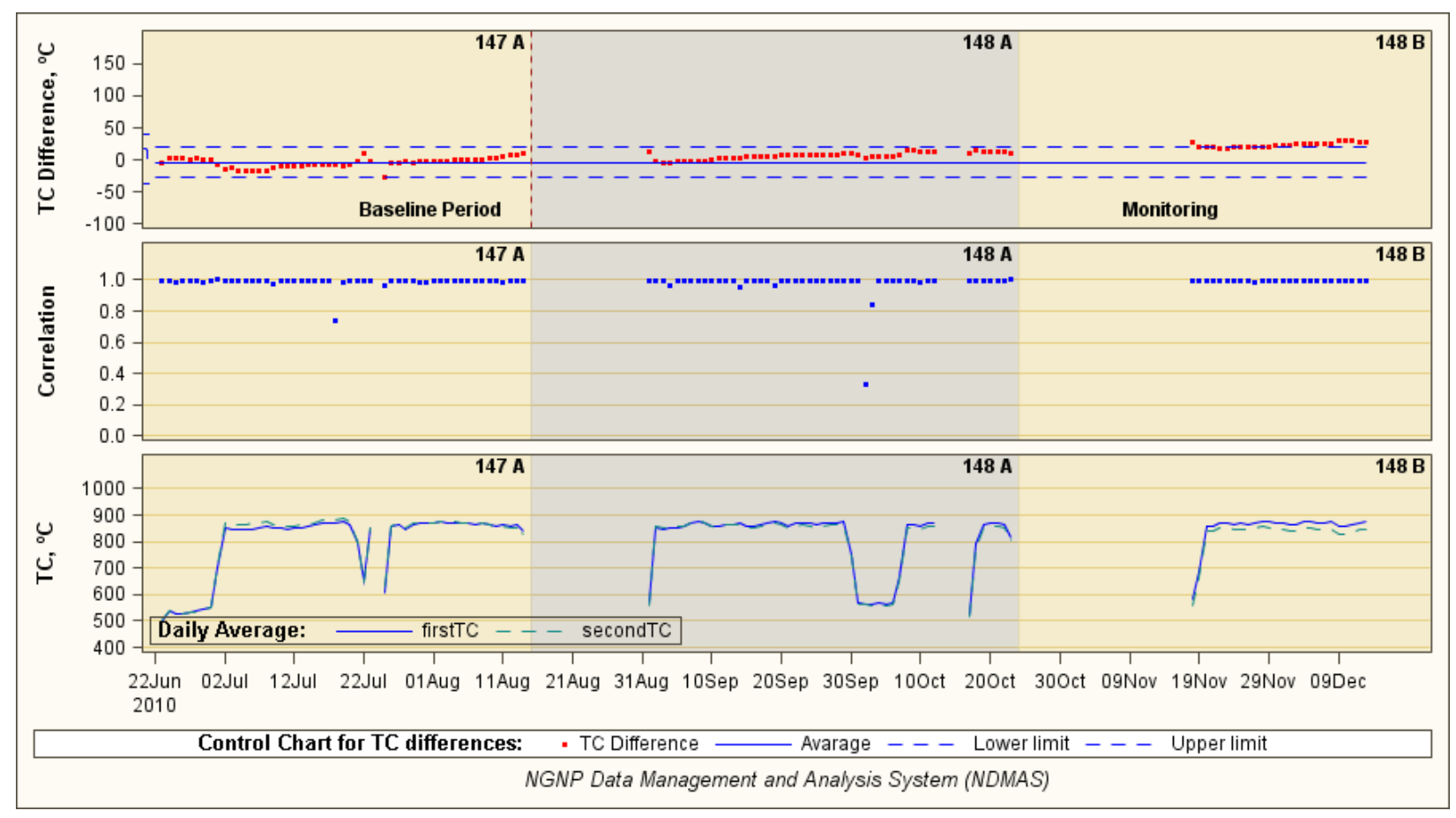

Figure 12. Drift monitoring for TC1 and TC2 in Capsule 5 during the first three cycles. 


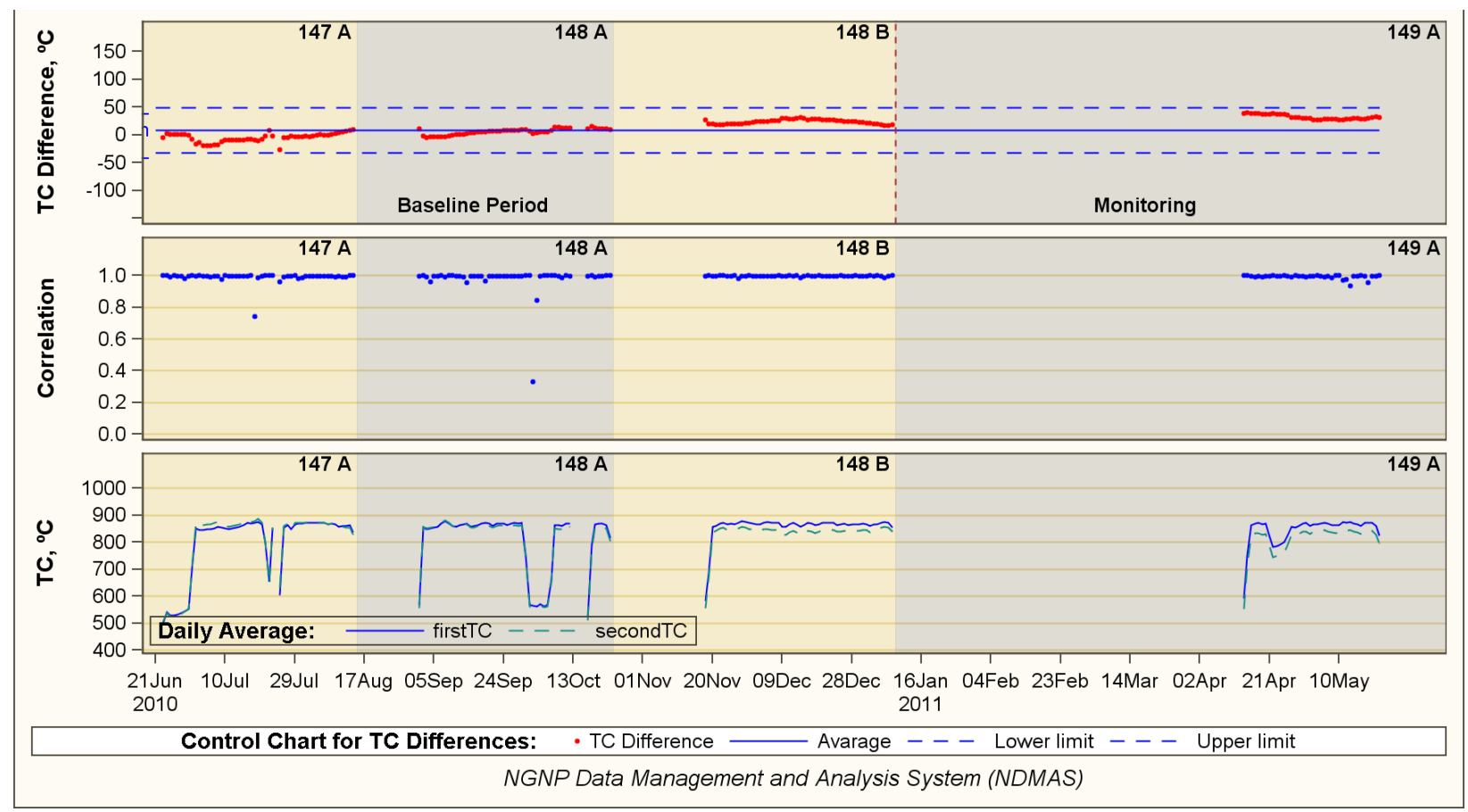

Figure 13. Drift monitoring for TC1 and TC2 in Capsule 5 - through Cycle 4.

\subsubsection{Control Chart Results-Capsule 6}

At the end of Cycle 3 in January 2011, TC4 in Capsule 6 was reported to have drifted about $70-80^{\circ} \mathrm{C}$ in relation to the other TCs $(1,2$, and 3) in that capsule as shown in Figures 14-16. At the same time, the other three TCs consistently followed each other. The drift pattern showed early cycle agreement followed by increasing drift later in each cycle, a pattern that continued through the fourth cycle as shown in Figure 17. This repeating pattern suggests that there may be other physical processes that may be causing TC4 to read hotter than the other TCs as each cycle progresses.

DRC Recommendation: No failure of data indicated from control chart drift for TCs in Capsule 6. 


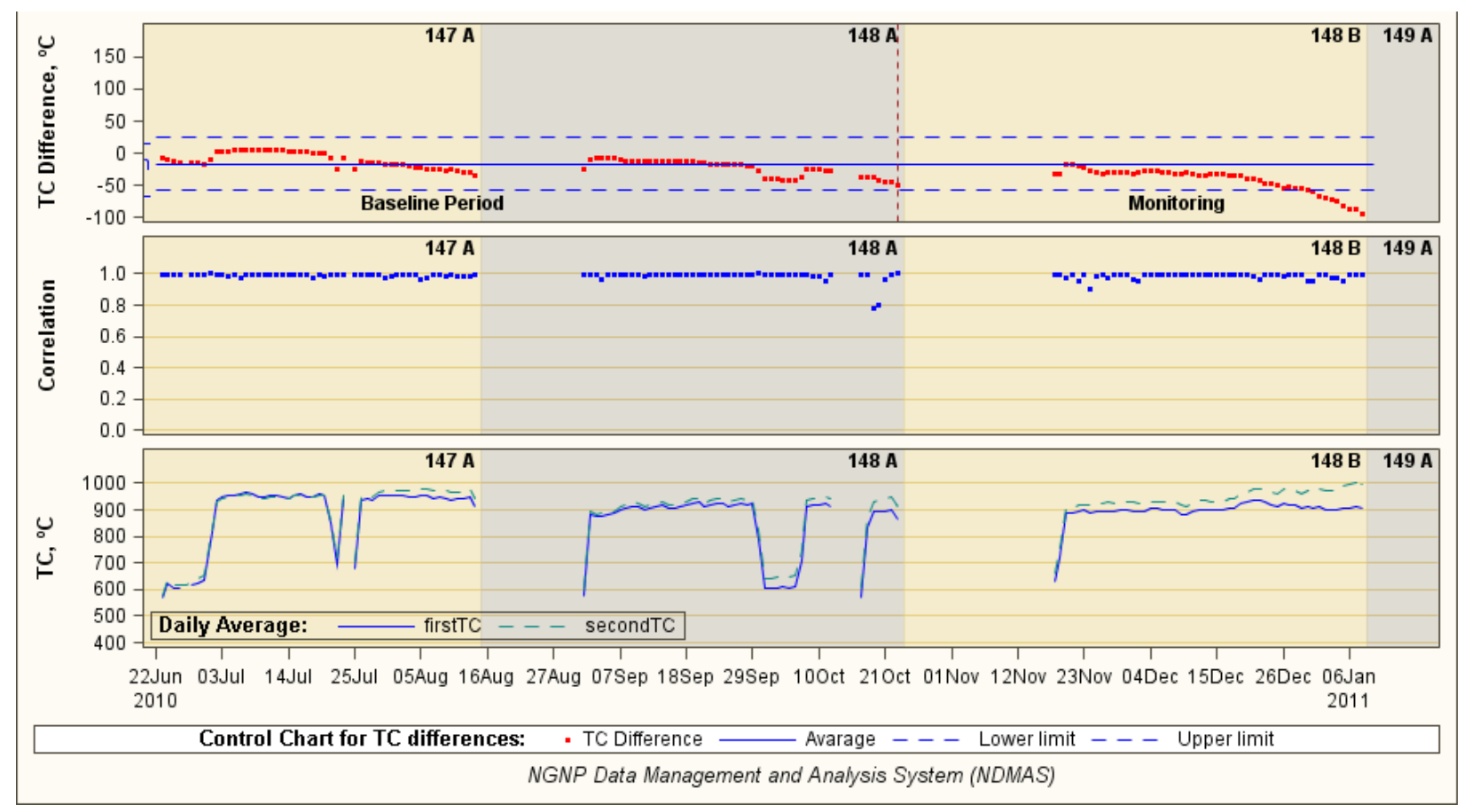

Figure 14. Drift monitoring for TC1 and TC4 in Capsule 6 through the third cycle. The TC difference (upper frame) is calculated as TC1-TC4. In the lower frame, TC4 is the dashed green line.

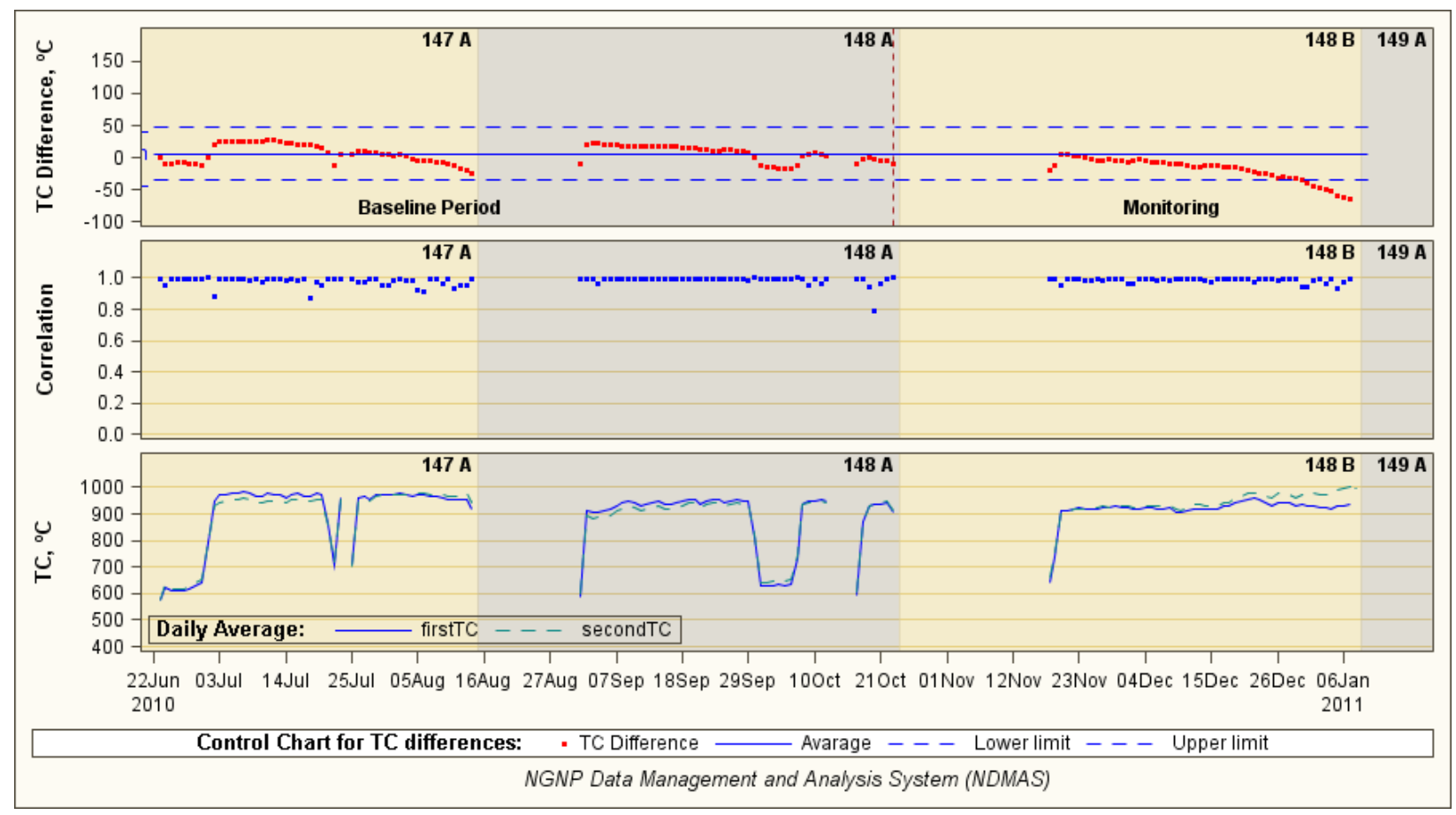

Figure 15. Drift monitoring for TC2 and TC4 in Capsule 6 through the third cycle. The TC difference (upper frame) is calculated as TC2-TC4. In the lower frame, TC4 is the dashed green line. 


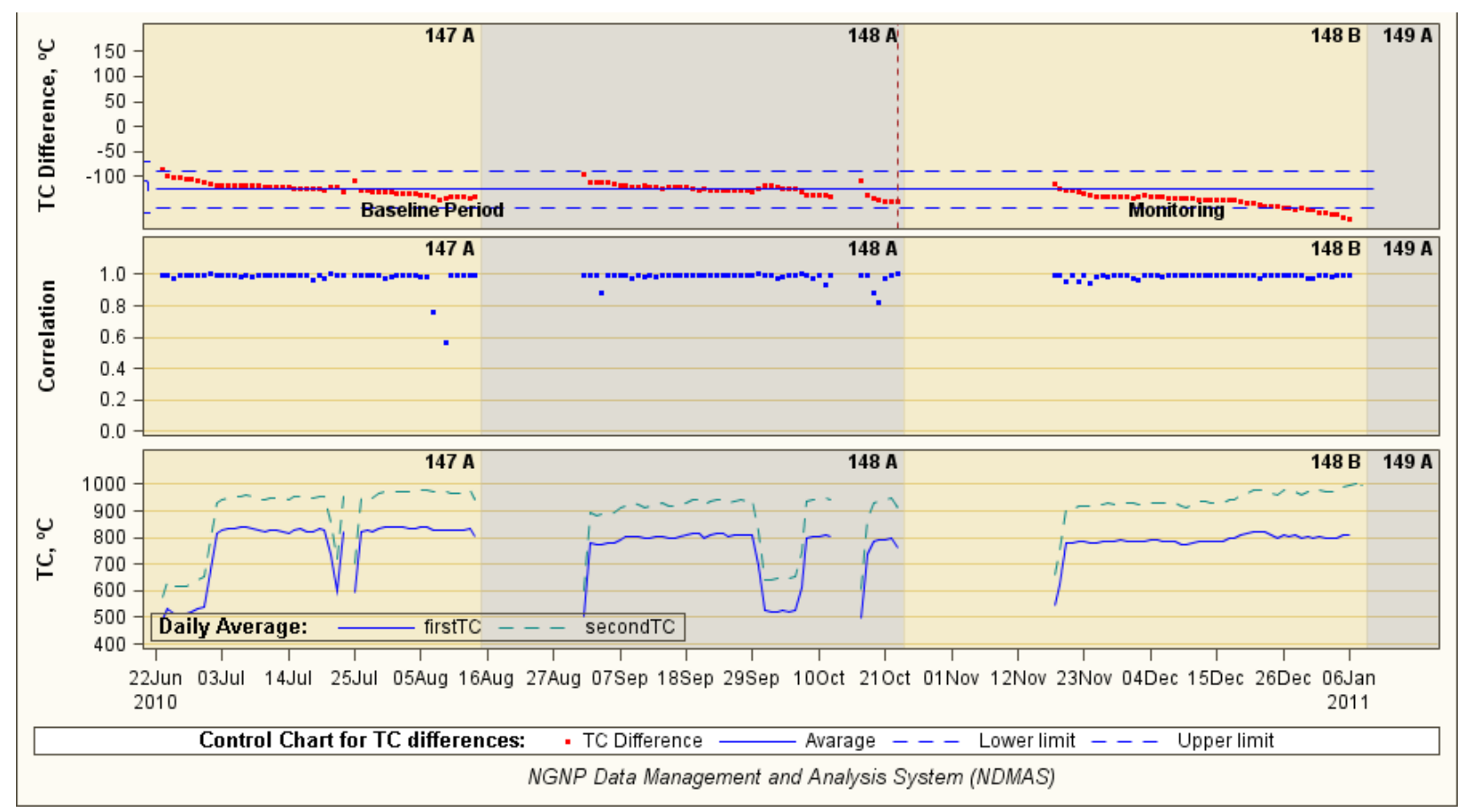

Figure 16. Drift monitoring for TC3 and TC4 in Capsule 6 through the third cycle. The TC difference (upper frame) is calculated as TC3-TC4. In the lower frame, TC4 is the dashed green line.

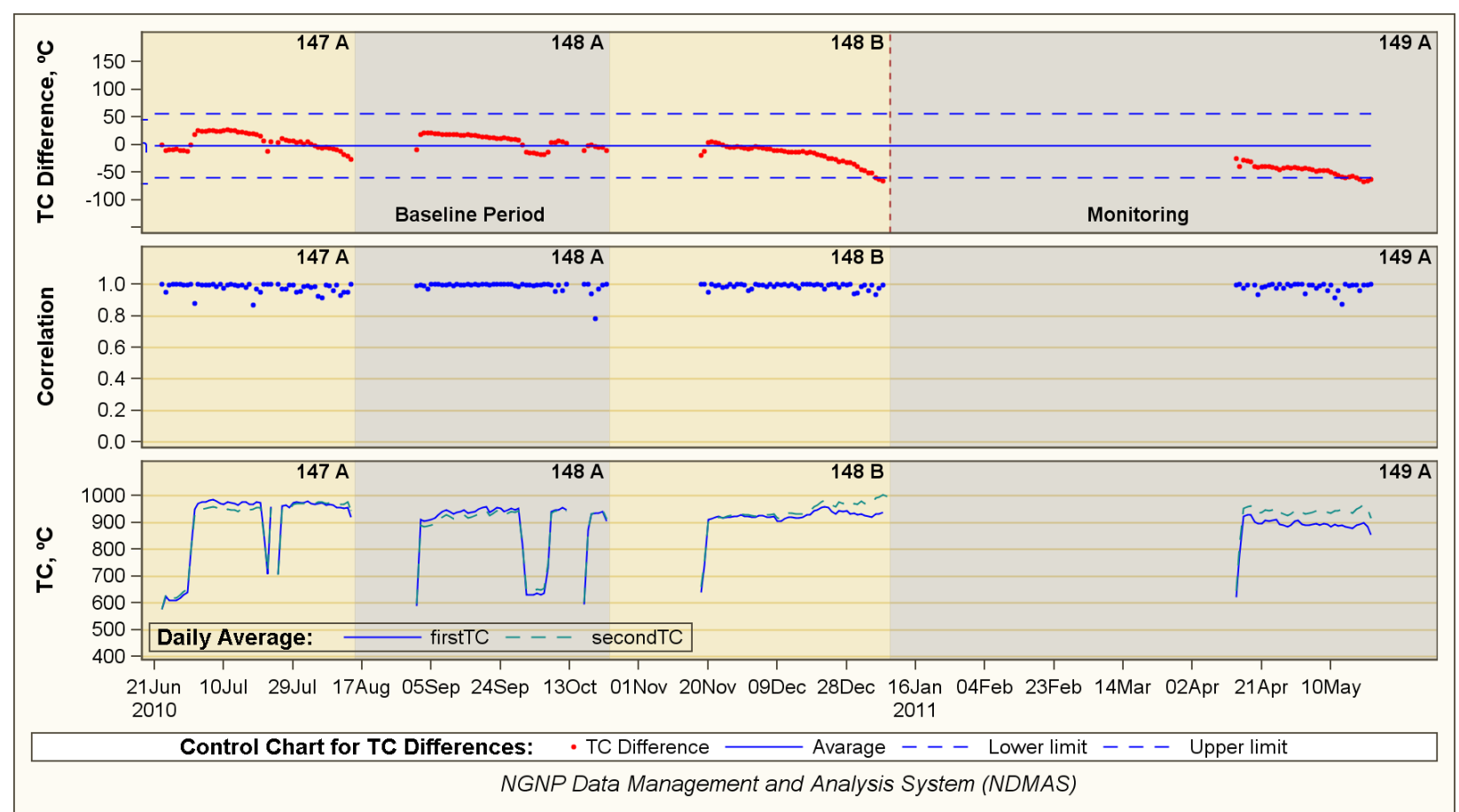

Figure 17. Drift monitoring for TC2 and TC4 in Capsule 6 through the fourth cycle. The TC difference (upper frame) is calculated as TC2-TC4. In the lower frame, TC4 is the dashed green line. 


\subsubsection{Correlation Analysis-TC Virtual Junctions}

NDMAS developed a simple correlation test to identify possible virtual junction failures in TCs. A virtual junction occurs when a TC starts to measure temperature at a different location than the designed TC location (e.g., in a higher elevation capsule where the TC wire runs through). During AGR-1, a number of the TCs formed virtual junctions outside the capsule in which they were installed, causing them to give erroneous readings (Pope 2010).

The correlation test examines the correlation coefficients between the daily averaged TC temperatures in all capsules. When functioning properly, TC readings for a given capsule should be most highly correlated with other TCs in the same capsule. If a virtual junction occurs, the highest correlation will switch to the TC readings in a different capsule (where the junction occurs). To do this test for a given capsule, there needs to be at least two functioning TCs located in that capsule. Figure 18 shows an example plot of the correlation coefficients for TCs 1 and 2 in Capsule 5. This plot shows that, for most days, the highest correlations for each of the TCs in Capsule 5 are with the other TC in Capsule 5, indicating no virtual junction. An examination of all the plots for functioning TCs (not included here) show similar results, indicating no apparent virtual junctions in any of the AGR-2 capsules.

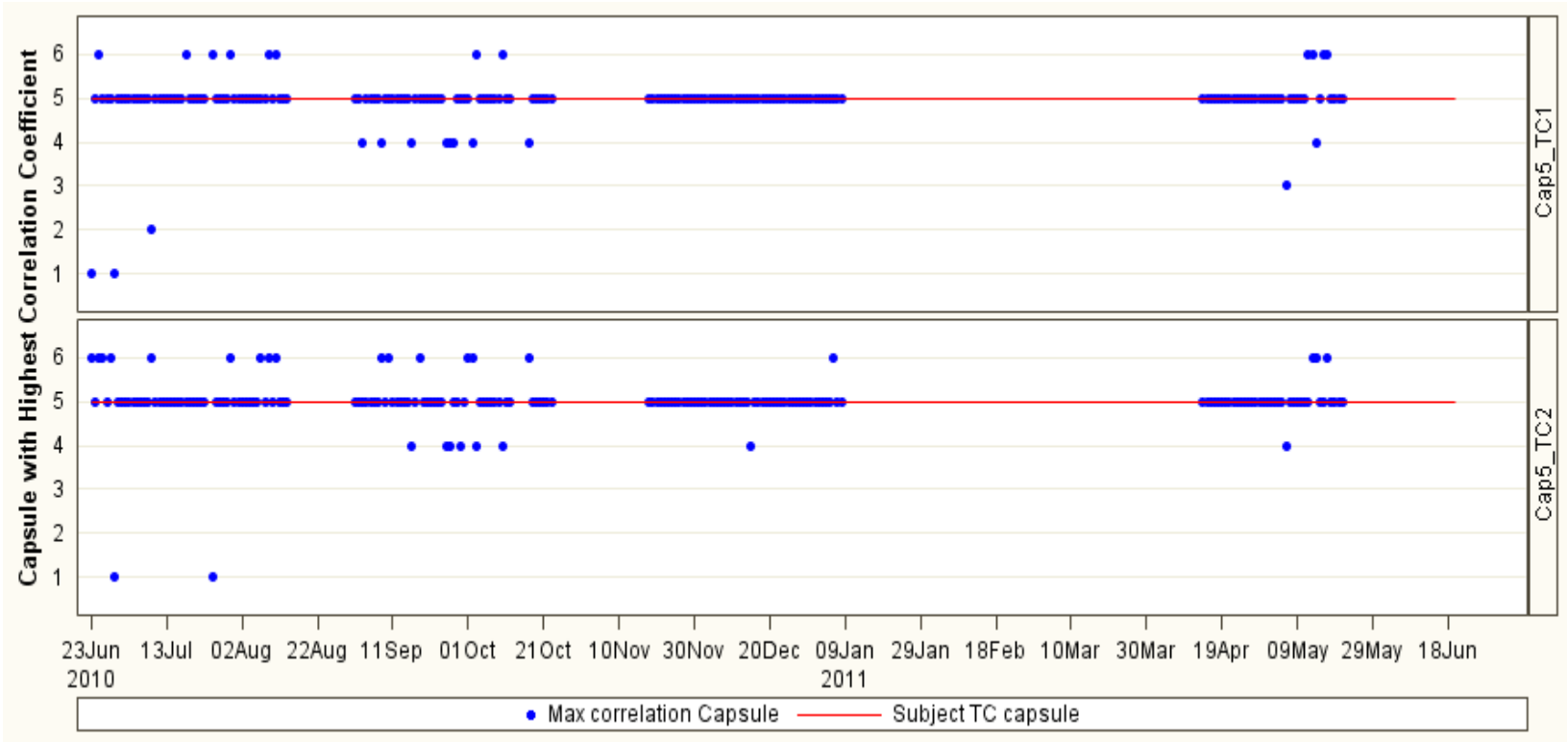

Figure 18. Example correlation plot for the TCs $(1,2)$ installed in Capsule 5. Both TCs are most highly correlated with the other TC in the same capsule, indicating no virtual junction. 


\section{NQA-1 CONFORMANCE}

Qualified data must be collected in accordance with data collection plans that are NQA-1 compliant. Compliance for the irradiation monitoring addressed in this report with data collection plans were independently verified on August 9, 2011, by a DRC comprised of AGR technical leads, NGNP QA, an independent peer reviewer, and NDMAS analysts.

The data collection requirements are documented in the following QA-approved plans, procedures, specifications, software user guides, and ECARs, which implement NQA-1 requirements for the NGNP Project:

Program Documents

- PLN-269, "VHTR TDO Quality Assurance Project Plan”

- PLN-2021, "Quality Assurance Program Plan for the Next Generation Nuclear Plant Project"

- MCP-2691, "Data Qualification”

- MCP-3058, "NGNP Software Quality Assurance"

AGR Experiment Documents

- PLN-3636, "AGR Technical Program Plan”

- SPC-1064, "AGR-2 Irradiation Test Specification"

- PLN-3798, “AGR-2 Irradiation Experiment Test Plan.”

FPMS Documents (all approved by VHTR Technology Development Office QA Lead)

- PLN-3551,"Fission Product Monitoring System Operability Test Plan for the AGR Experiment."

- GDE-503, "Users' Guide for the Fission Product Monitoring System."

- ECAR-1348, "Preliminary Release-to-Birth Ratios for Operating Cycle 147A," Rev. 0, February 3, 2011.

- ECAR-1355, "Preliminary Release-to-Birth Ratios for Operating Cycle 148A,” Rev. 0, February 23, 2011.

- ECAR-1412, "Preliminary Release-to-Birth Ratios for Operating Cycle 148B," Rev. 0, March 14, 2011. 


\section{DATA RECORD QUALIFICATION SUMMARY}

This section summarizes the data qualification decisions for the data packages received by NDMAS from June 19, 2010, through May 23, 2011, which encompass the AGR-2 start date for Cycle 147A of June 22, 2010, and the finish date for the fourth reactor cycle (149A) of May 21, 2011. Detailed information on the data and the technical basis for the decisions is discussed in Section 3.

\subsubsection{Irradiation Monitoring Data (TC and Sweep Gas)}

A total of 2,439,138 10-min irradiation monitoring records were received by NDMAS for the first four reactor cycles for all six capsules as shown in Table 7. Of these data, 95.5\% met the requirements for data collection and are labeled Qualified. For TC data, there were 109,038 Failed records due to instrument failure and 4 Failed records due to range test failure (see section 3 for details). For the sweep gas data, there were 568 "He-in" and 99 "Q_Mix_Out" records that failed NDMAS range testing (Section 3, Table 6). All of these gas data were reexamined and determined to be Qualified.

Table 7. Summary of the qualification status of the 10-min irradiation monitoring records (TC and sweep gas data) received by NDMAS during the first four ATR cycles.

\begin{tabular}{|c|c|c|c|c|c|c|}
\hline \multirow[b]{2}{*}{ Data Package Dates } & \multirow[b]{2}{*}{ Total Received } & \multirow[b]{2}{*}{ TC Failures } & \multicolumn{4}{|c|}{ Range Test Failures $^{\mathrm{a}}$} \\
\hline & & & TCs & $\mathrm{He}$ In & Q_Mix Out & Qualified $^{a}$ \\
\hline 19JUN to $24 J U N 10$ & 15,288 & 312 & 0 & 0 & 0 & 14,976 \\
\hline $21 \mathrm{JUN}$ to $28 \mathrm{JUN} 10$ & 49,686 & 1014 & 1 & 0 & 0 & 48,671 \\
\hline 28JUN to $05 J U L 10$ & 49,392 & 1007 & 1 & 0 & 0 & 48,384 \\
\hline 05JUL to 12 JUL 10 & 49,392 & 1008 & 0 & 0 & 0 & 48,384 \\
\hline 12JUL to $19 \mathrm{JUL} 10$ & 49,392 & 1008 & 0 & 0 & 0 & 48,384 \\
\hline 19JUL to $02 \mathrm{AUG} 10$ & 98,789 & 2016 & 0 & 5 & 0 & 96,773 \\
\hline 02AUG to 09AUG10 & 49,392 & 1008 & 0 & 0 & 0 & 48,384 \\
\hline 09AUG to 06SEP10 & 197,568 & 4032 & 0 & 0 & 0 & 193,536 \\
\hline 06SEP to 20SEP10 & 98,784 & 2016 & 0 & 0 & 0 & 96,768 \\
\hline 20SEP to $04 \mathrm{OCT} 10$ & 98,784 & 2016 & 0 & 0 & 0 & 96,768 \\
\hline $04 \mathrm{OCT}$ to $11 \mathrm{OCT} 10$ & 49,392 & 1008 & 0 & 0 & 17 & 48,384 \\
\hline $11 \mathrm{OCT}$ to $08 \mathrm{NOV} 10$ & 197,328 & 7464 & 0 & 54 & 82 & 189,864 \\
\hline $08 \mathrm{NOV}$ to $29 \mathrm{NOV} 10$ & 148,648 & 6324 & 1 & 178 & 0 & 142,323 \\
\hline $29 \mathrm{NOV}$ to $13 \mathrm{DEC} 10$ & 98,784 & 6048 & 0 & 0 & 0 & 92,736 \\
\hline 13DEC10 to 3JAN11 & 148,176 & 9072 & 0 & 0 & 0 & 139,104 \\
\hline 03JAN to 10JAN11 & 49392 & 3024 & 0 & 209 & 0 & 46,368 \\
\hline 11APR to 18 APR11 & 496,909 & 30421 & 1 & 0 & 0 & 466,487 \\
\hline 18APR to $25 \mathrm{APR} 11$ & 98784 & 6048 & 0 & 0 & 0 & 92,736 \\
\hline 5APR to 02MAY11 & 98,784 & 6048 & 0 & 0 & 0 & 92,736 \\
\hline 02MAY to 09MAY11 & 98784 & 6048 & 0 & 0 & 0 & 92,736 \\
\hline 09MAY to 16MAY11 & 98784 & 6048 & 0 & 0 & 0 & 92,736 \\
\hline 16MAY to 23MAY11 & 98,906 & 6048 & 0 & 122 & 0 & 92,858 \\
\hline Total & $2,439,138$ & 109,038 & 4 & 568 & 99 & $2,330,096$ \\
\hline
\end{tabular}




\subsubsection{FPMS Data}

As of this report publication, NDMAS has received and processed release rate and preliminary R/B data for the first three reactor cycles (147A, 148A, and 148B). This consists of 16,536 release rates records and $12,000 \mathrm{R} / \mathrm{B}$ records for the 12 radionuclides reported (1,378 release rate records and 1,000 $\mathrm{R} / \mathrm{B}$ records for each radionuclide). There are an equivalent number of error (\%) records associated with these records. All of these data have been capture passed, stored in the NDMAS vault, and made available on the NDMAS Web portal. The qualification status of these data has been set to Qualified based on receipt of QA-approved ECARs Nos. 1348, 1355, and 1412. The processed R/B data are classified as "preliminary" by the FPMS staff, which means they are subject to change if revised simulated birth rate data become available. 


\section{DATA ACCESS}

The irradiation monitoring data and data qualification status are available on the NDMAS Web portal (http://ndmas.inl.gov) for easy, secure access by NGNP Project participants as shown in Figure 19. The website is organized by experiment (e.g., AGR-2), data stream (e.g., FPMS), and type of analysis (e.g., gas flows, temperature). These Web pages (blue bar on left in Figure 18) have numerous content types, including static plots/images, direct links to data files, SAS ${ }^{\circledR}$ reports that can be interactively queried (e.g., sorted or filtered by capsule or date interval), and reports with data "drill-down" and download options.

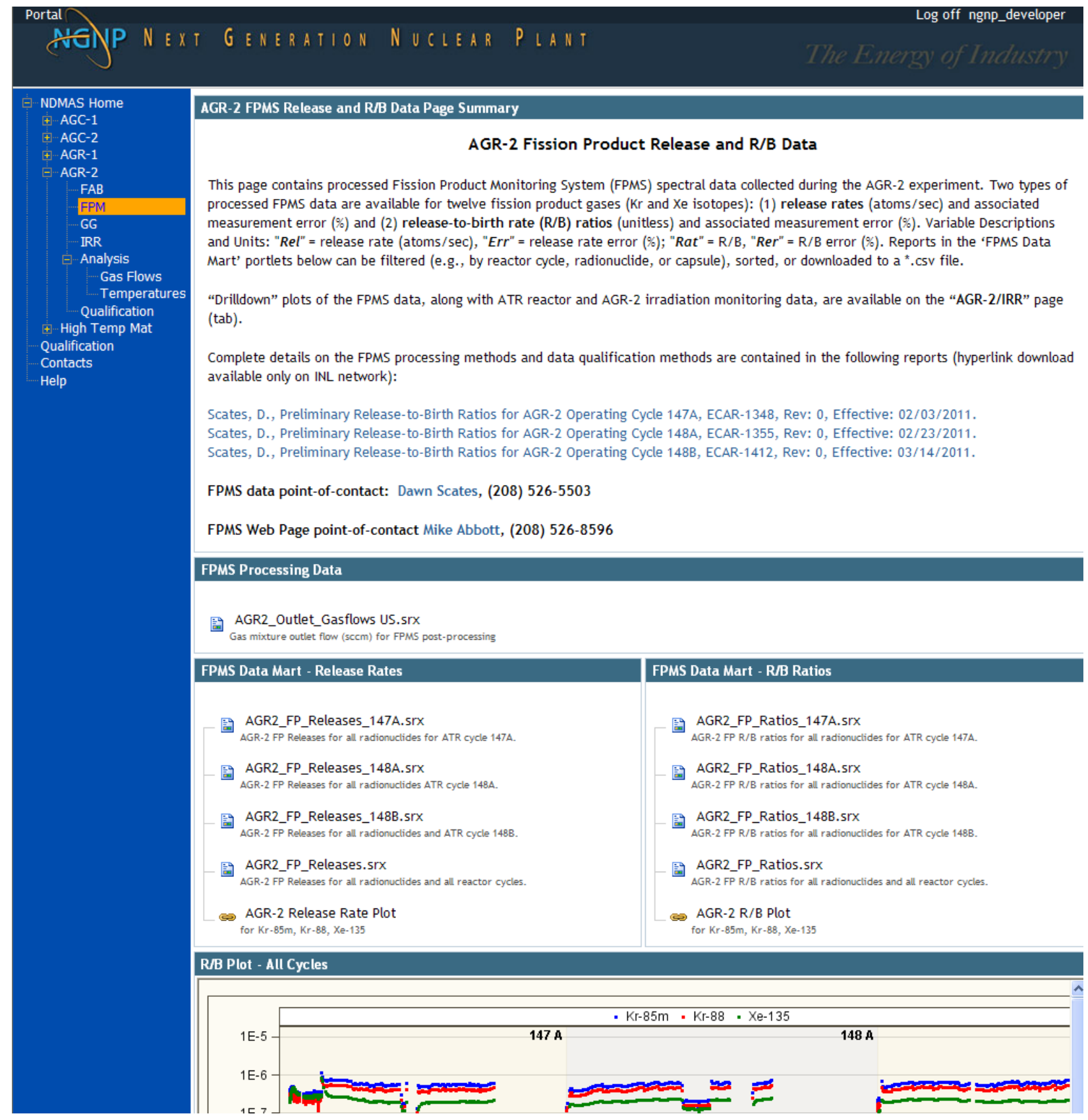

Figure 19. The AGR-2 Web page (in blue bar on left) on the NDMAS Web portal provides access to numerous types of data reports, graphs, and images. 


\section{REFERENCES}

Abbott, M. L., L. C. Hull, B. Pham, and M. A. Plummer, 2010, AGR-1 Data Qualification Report, INEL/EXT-10-17943, Idaho National Laboratory, Idaho Falls, ID, 55 p.

ASME NQA-1-2008, 1a 2009, "Quality Assurance Requirements for Nuclear Facility Applications.”

MCP-2691, "Data Qualification,” Idaho National Laboratory, Idaho Falls, ID, 30 p.

MCP-3058, "NGNP Software Quality Assurance," Rev. 0, Idaho National Laboratory, Idaho Falls, ID, $44 \mathrm{p}$.

PLN-1485, "Records Management Plan for Next Generation Nuclear Plant (NGNP) Project," Rev. 10, Idaho National Laboratory, Idaho Falls, ID, 17 p.

PLN-2021, "Quality Assurance Program Plan for the Next Generation Nuclear Plant Project," Rev. 10, Idaho National Laboratory, Idaho Falls, ID, 40 p.

PLN-2690, “VHTR Technology Development Office Quality Assurance Program Plan,” Rev. 7, Idaho National Laboratory, Idaho Falls, ID, 49 p.

PLN-2709, "Very-High-Temperature-Reactor Program Data Management and Analysis Plan," Rev. 3, Idaho National Laboratory, Idaho Falls, ID, 25 p.

PLN-3551, "Fission Product Monitoring System Operability Test Plan for the AGR Experiment," Rev. 0, Idaho National Laboratory, Idaho Falls, ID, 21 p.

PLN-3636, "Technical Program Plan for the Next Generation Nuclear Plant/Advanced Gas Reactor Fuel Development and Qualification Program," Rev. 0, 109 p.

PLN-3798, “AGR-2 Irradiation Experiment Test Plan,” Rev. 0, Idaho National Laboratory, Idaho Falls, ID, $45 \mathrm{p}$.

Pope, M. A., 2010, AGR-1 Irradiation Test Final as-Run Report, INL/EXT-10-18097, Idaho National Laboratory, Idaho Falls, ID, 85 p.

SPC-1064, “AGR-2 Irradiation Test Specification,” Rev. 1, Idaho National Laboratory, Idaho Falls, ID, $17 \mathrm{p}$. 
Appendix A

\section{Credentials of Technical Reviewer}




\section{Appendix A-Credentials of Technical Reviewer}

\section{Credentials for Matthew Weseman}

Matthew Weseman has 32 years experience in: designing, developing, and producing instrumentation and process control (I\&C) systems; project engineering/management for numerous I\&C tasks; research, analysis, design and testing activities performed for the commercial, military, and nuclear industries; and extensive involvement in generating project and program proposals involving determining specifications, preliminary design, and presentation (selling the idea) to the customer/upper management. He is currently an Advisory Engineer for the Defense Systems and Technologies (Process Instrumentation \& Controls subsection) of Battelle Energy Alliance, LLC (INL prime contractor) where he performs project engineering, design, installation, and operation of various process control and instrumentation systems, including: data acquisition, control, instrumentation, communication (wireless), networked, programmable logic controllers, and man-machine interface systems. Responsibilities include system requirements, design, hardware installation, maintenance, software verification, documentation, and design verification and qualification testing and modifications. Matt coordinates electronic, electrical, mechanical, and pneumatic instrumentation and control systems and is a project engineer/manager of new experiments and control system integration and installation. Matt specializes in groundwater and contaminated and chemical waste cleanup systems. 